\title{
Aging Test Results of An Asphalt Membrane Liner
}

J. L. Buelt

S. M. Barnes

July 1983

Prepared for the U.S. Department of Energy under Contract DE-AC06-76RLO 1830

Pacific Northwest Laboratory Operated for the U.S. Department of Energy by Battelle Memorial Institute 


\title{
DISCLAIMER
}

This report was prepared as an account of work sponsored by an agency of the United States Government, Neither the United States Government nor any agency thereof, nor any of their employees, makes any warranty, express or implied, or assumes any legal liability or responsibility for the accuracy, completeness, or usefulness of any information, appararus, product, or process disclosed, or represents that its use would notinfringe privately owned rights. Reference herein to any specific commercial product, process, or service by trade name, trademark, manufacturer, or othenwise, does not necessarily constitute or imply its endorsement, recommendation, or favoring by the United States Government or any agency theteof. The views and opinions of authors expressed herein do not necessarily state or reflect those of the United States Covernment or any agency thereot.

\author{
PACIFIC NORTHWEST LABORATORY \\ operated by \\ BATTELLE \\ for the \\ UNITED STATES DEPARTMENT OF ENERGY \\ under Contract DE-AC06-76RLO 1830
}

\begin{tabular}{|c|c|}
\hline \multicolumn{2}{|c|}{ Printed in the Unined States of Amierica } \\
\hline \multicolumn{2}{|c|}{ Avallable from } \\
\hline \multicolumn{2}{|c|}{ National Technical Information Service } \\
\hline \multirow{3}{*}{\multicolumn{2}{|c|}{$\begin{array}{l}\text { United Srates Departmnet of Commerce } \\
5225 \text { Port Royal Road } \\
\text { Springtield / Virginia 2216) }\end{array}$}} \\
\hline & \\
\hline & \\
\hline \multirow{2}{*}{\multicolumn{2}{|c|}{$\begin{array}{l}\text { Nns Frice Codes } \\
\text { Micraliche A01 }\end{array}$}} \\
\hline & \\
\hline \multicolumn{2}{|c|}{ Printed Copr } \\
\hline & Price \\
\hline Pares & Codes \\
\hline Dot-925. & A02 \\
\hline $085: 050$ & Aas \\
\hline c5i-0s & $\mathrm{AOH}$ \\
\hline $006-100$ & Nos \\
\hline 101.285 & Nos \\
\hline $1.6-190$ & AD? \\
\hline 131.175 & 106 \\
\hline $176-290$ & $A 69$ \\
\hline $201-225$ & 1010 \\
\hline $236-230$ & A011 \\
\hline 251.275 & $\mathrm{Am} 2$ \\
\hline $276-900$ & nas) \\
\hline
\end{tabular}


PNL -4752

UC-70

DOE/UMT -0064

AGING TEST RESULTS OF AN

ASPHALT MEMBRANE LINER

J. L. Buelt

S. M. Barnes

July 1983

Prepared for

the U.S. Department of Energy

under Contract DE-AC06-76RLO 1830

Pacific Northwest Laboratory

Richland, Washington 99352 
-

,

- 


\section{SUMMARY}

The objective of the asphalt aging study described in this report was to determine the expected performance lifetime of a catalytically airblown asphalt membrane as a seepage barrier for inactive uranium mill tailings. The study, conducted by Pacific Northwest Laboratory for the Department of Energy's Uranium Mill Tailings Remedial Action Program, showed through chemical compatibility tests that the asphalt membrane is well suited for this purpose. The chemical compatibility tests were designed to accelerate the aginy reactions in the asphalt and to determine the accelerated aging effect. Higher temperatures and oxygen concentrations proved to be effective acceleration parameters.

By infrared spectral analysis, the asphalt was determined to have undergone 7 years of equivalent aging in a 3 -month period when exposed to $40^{\circ} \mathrm{C}$ and 1.7 atm oxygen pressure. However, the extent of aging was limited to a maximum penetration of $0.5 \%$ of the total liner thickness. It was concluded that the liner could be expected to be effective as a seepage barrier for at least 1000 years before the entire thickness of the liner would be degraded. 
. 


\section{CONTENTS}

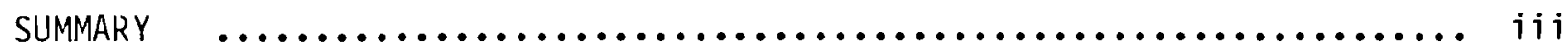

INTRODUCTION

CONCLUSIONS

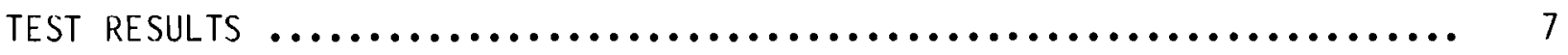

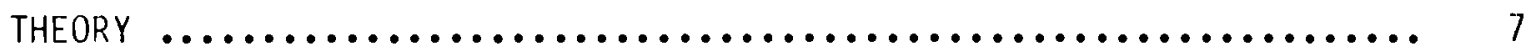

EXPOSURE COLUMNS $\ldots \ldots \ldots \ldots \ldots \ldots \ldots \ldots \ldots \ldots \ldots \ldots \ldots \ldots \ldots \ldots, g^{9}$

EXPOSURE CONDITIONS $\ldots \ldots \ldots \ldots \ldots \ldots \ldots \ldots \ldots \ldots \ldots \ldots \ldots \ldots, 11$

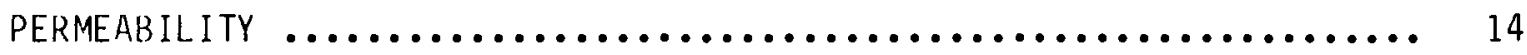

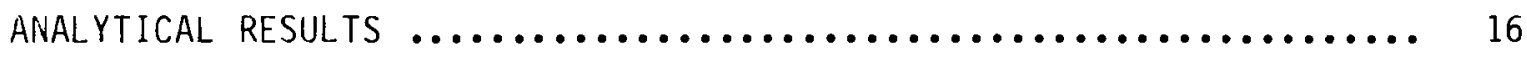

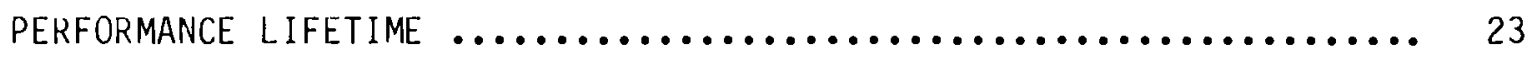

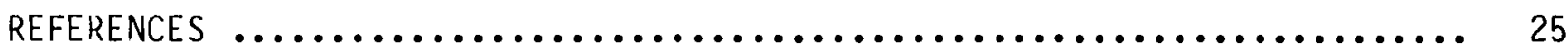

APPENDIX - EXPOSURE CONDITIONS, PERMEABilities, AND REACTION RATES ...... A.I 


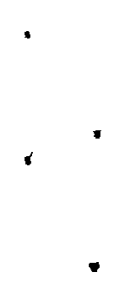




\section{FIGURES}

1 Distributor Truck Applying Asphalt Membrane ................. 3

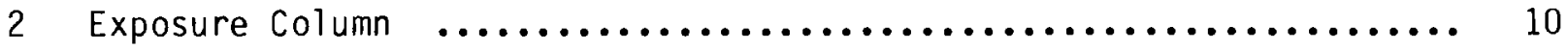

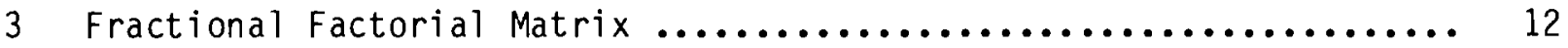

4 Permeability of Asphalt Liner at Normal and Intermediate

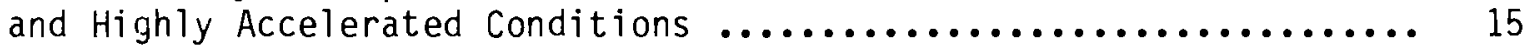

5 Absorption Bands of 0.C.T., Paraplast, and Asphalt ............. 18

6 Reaction Rates at Normal and Highly Acidic Conditions ............ 19

7 Effect of Temperature on Reaction Rates

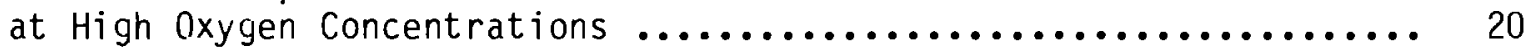

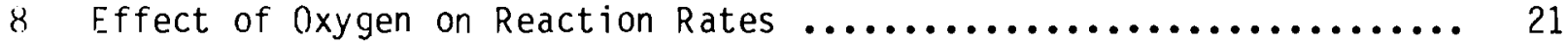

9 Reaction Rates at Intermediate Exposure Conditions ............ 22

\section{TABLE}

1 Simulated Tailings Leachate Composition .................... 11 
,

- 
INTRODUCTION

In 1978, Congress passed Public Law 95-604 requiring the final disposal of twenty-four inactive uranium mill tailings piles in the United States

(Department of Energy 1982). In response, the Department of Energy created the Uranium Mill Tailings Remedial Action Program (UMTRAP). One of the program's responsibilities included developing the technology necessary for remedial action of the tailings piles and vicinity properties in conformance with reyulatory standards established by the Environmental Protection Agency (EPA). The anticipated regulations led to the inception of the liner technology program supported by UMTRAP in 1980 .

Pacific Northwest Laboratory (PNL) was contracted to develop liner technology for the long-term remedial action of these uranium mill tailings sites. More recently, it became apparent through the liner technology and hydrological studies conducted for UMTRAP that the natural retarding factors in the foundation soils at these sites are, in most cases, enough to protect the groundwater (Relyea and Martin 1982). Only in certain circumstances would special liner technology be required for long-term remedial action. One such circumstance might include alkaline tailings near a shallow groundwater table in a permeable or cracked foundation soil, since the natural retarding factors for soils are diminished for alkaline leachates. Even though the application of liners to inactive sites will be limited, the PNL liner program, addressed in this report, has provided significant technological background applicable to UMTRAP and elsewhere.

The PNL liner program is comprised of four tasks. The first, a decision tree development task, was completed in FY 1982. It outlined a logical approach for determining the need or type of liner required at a disposal site through the use of hydrological models (Relyea 1983). In the second task, soil and clay liner interaction studies were performed with leachates. Accelerated aging tests of an asphalt membrane liner were conducted in the program's third task. The fourth task demonstrated the application and longevity of selected liners in the field. By the end of FY 1983, the four task's activities have been or will be finished, signifying the completion of the PNL development 
program for liner technology. This report is the final report dealing with the activities in Task 3, which completes the asphalt liner aging tests.

Early in the program, screening studies were conducted to determine the most prospective asphalt liner materials (Buelt et al. 1981; Barnes, Buelt and Hale 1981). As a result, a catalytically airblown asphalt membrane was determined to be the most stable and cost-effective asphalt liner material of those tested. The asphalt membrane is 7 to $8 \mathrm{~mm}$ thick and is applied at about $200^{\circ} \mathrm{C}$ through an asphalt distributor truck, as shown in Figure 1 . The asphalt is specially formulated in the production process to resist aging reactions; it is airblown in the presence of a catalyst, usually phosphoric oxide or ferric chloride. This procedure not only resists aging reactions, but also promotes proper viscosity relationships for use as a lining material. Proper viscosity is necessary to prevent cold flow on slopes but still be elastic enough to yield to stresses caused by foundation soil subsidence. Besides having advantageous chemical and physical properties, the catalytic airblown asphalt has a good historical use record in canal linings (Geir and Morrison 1968). It has not only been considered for uranium mill tailings liners but also as a cover material for the disposal of low-level radioactive wastes (Tucker 1983). Composed of naturally occurring components, the asphalt membrane is expected to have a greater expected lifetime than synthetic geomembranes. Thus, it was selected for more comprehensive testing.

The primary purpose of the study described in this report is to quantify the expected performance lifetime of catalytic airblown asphalt in contact with conditions that might be expected over the long term (1000 years) at a uranium mill tailings impoundment. To make that determination, accelerated aging tests were devised. This report discusses the results of these accelerated chemical compatibility tests. It does not, however, discuss the engineering aspects of installing a catalytic airblown asphalt membrane. They have been addressed widely in the literature and will be discussed in the final programmatic report to be issued later this fiscal year. 


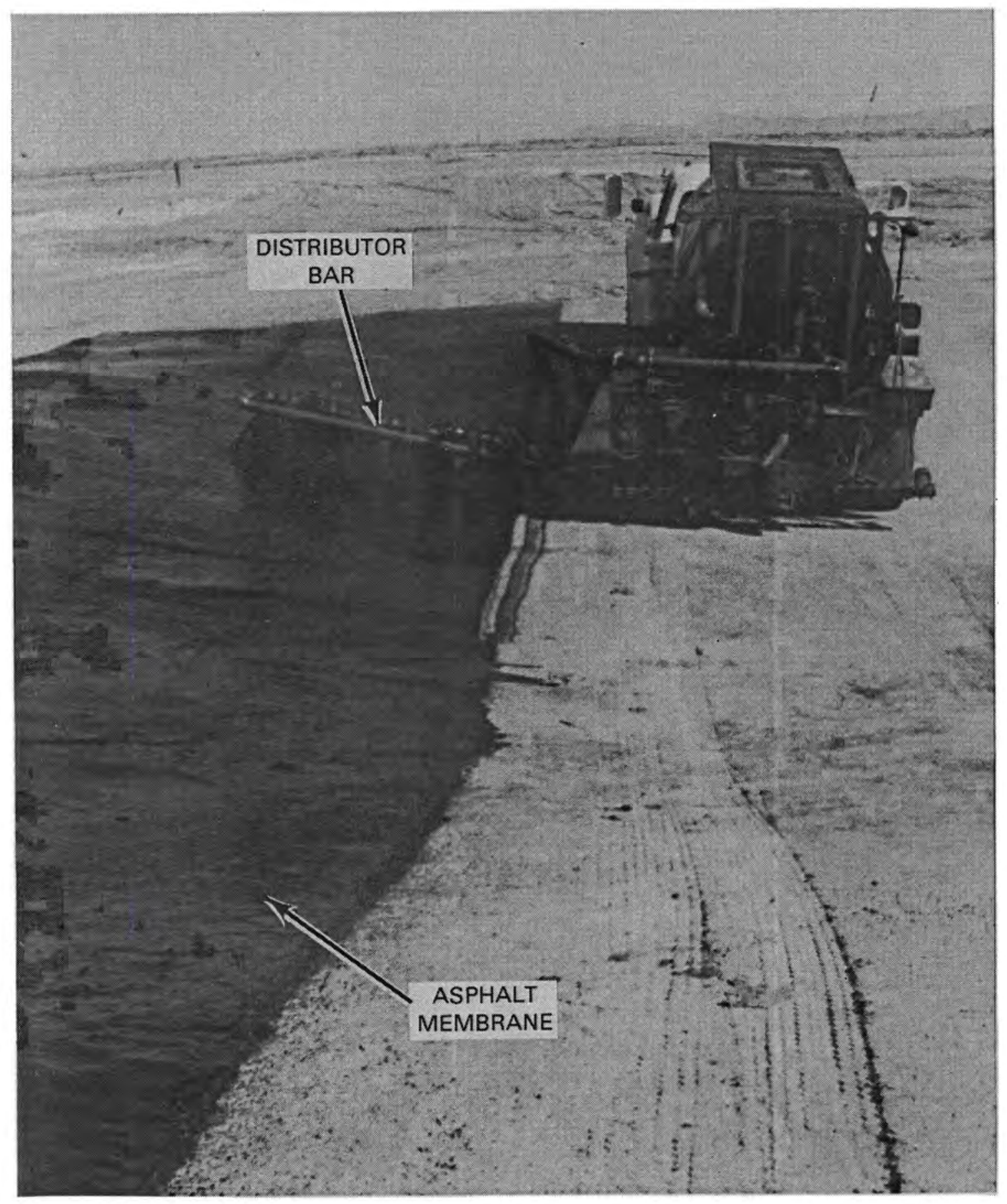

FIGURE 1. Distributor Truck Applying Asphalt Membrane 


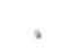

, 


\section{CONCLUSIONS}

The results of the accelerated aging study have shown that by extrapolating the test data, the lifetime of the catalytic airblown asphalt membrane as an effective leachate barrier for inactive uranium mill tailings is greater than 1000 years. This is determined by infrared spectrometric analysis of aged asphalt samples. Infrared spectrometry identifies the carbonylcontaining components, which are the reaction products of aging reactions. With time, the carbonyls normally combine with other long-chain asphalt molecules that increase the viscosity and hardness, making the asphalt more prone to brittle fracture.

This study successfully demonstrated that the aging of asphalt (formation of carbonyls) could be accelerated through the use of increased temperatures and oxygen concentrations. According to reaction rate measurements, the imposed temperature and oxygen concentrations produced an equivalent aging effect of 7 years over a 3-month period. We determined that for every increase of $10^{\circ} \mathrm{C}$, the reaction rate would increase by a factor of 2.3 . Oxygen contributed a significant effect as well. Increased acidity concentrations, however, were determined to have an unmeasurable effect on aging.

Aying reactions during the 3 -month exposure were limited to a penetration beyond the exposed asphalt surface of only 10 to $40 \mu \mathrm{m}$. This amounts to only 0.1 to $0.5 \%$ of the total membrane thickness. Extrapolating the penetration of the maximally exposed asphalt sample to the total membrane thickness gives an expected performance lifetime in excess of 1000 years.

Aging reactions were not discernible under normal, nonaccelerated conditions. This observation supports the conclusion that aging reactions can be accelerated. Even so, we can conclude that the degradation reactions, even at accelerated aging conditions, are extremely slow when exposed to mill tailings leachates. Therefore, the catalytic airblown asphalt membrane could serve as an effective leachate barrier for long-term management of uranium mill tailings, should the need arise. 



\section{TEST RESULTS}

Aging of asphalt results in physical hardening and embrittlement of the liner materials. The primary degradation known to occur due to aging is oxidation. Asphalt, when oxidized, is converted to longer chain hydrocarbons with the formation of carbonyls. The longer chained hydrocarbons are more viscous and brittle and are thus more easily prone to cracking from physical stresses that might be experienced at a tailings site over a long period (i.e. 1000 years). Therefore, it is important to quantify the rate of aging reactions and predict the condition of the asphalt liner after the 1000-year period. As a result, a methodology for accelerating the reaction rate over a reasonable period of time ( 3 months) was developed for this study.

$\underline{\text { THEORY }}$

The objective of the accelerated aying methodology is to increase the degradation reaction rates of an asphalt liner under simulated mill tailings impoundment conditions. To accomplish this, certain exposure conditions are selected, based on past studies, to accelerate the reaction mechanisms. The reaction rate is then determined and compared to those of less accelerated or normal conditions. This comparison is used to quantify the expected performance lifetime.

Van Dort (1956) and Blokker and van Hoorn (1959) have conducted studies previously on increasing the degradation rates of asphalt. Both studies used the following expression for the reaction rate:

$$
\mathrm{R}_{\mathrm{A}}=\mathrm{k}\left(\mathrm{C}_{\mathrm{O}_{2}}\right)^{n}
$$

where:

$$
\begin{aligned}
R_{A}= & \text { reaction rate of the component of interest } \\
k= & \text { the temperature dependent reaction rate constant } \\
C_{0_{2}}= & \text { concentration of oxygen } \\
n= & \text { the dependency of oxygen on reaction rate (referred to as the order } \\
& \text { of reaction). }
\end{aligned}
$$


The reaction rate constant is dependent upon temperature according to Arrhenius law (Levenspiel 1972):

$$
k=k_{0} e^{-E_{A} / R T}
$$

where:

$$
\begin{aligned}
k & =\text { reaction rate constant } \\
k_{0} & =\text { a proportionality constant } \\
E_{A} & =\text { activation energy } \\
R & =\text { gas law constant } \\
T & =\text { temperature. }
\end{aligned}
$$

Since the reaction rate constant is temperature dependent, Van oort experimented with temperature to increase the reaction rate. By conducting aging experiments in the absence of light, Van 0ort was able to determine the activation energy $E_{A}$ for asphalt experimentally. By plotting ln $k$ vs $1 / T$, he derived the activation energy at $24 \mathrm{kcal} / \mathrm{mole}$, which is a normal value for organic chemical reactions. At this activation energy, an increase in temperature of $10^{\circ} \mathrm{C}$ above ambient would be expected to increase the reaction rate by a factor of 4.3 .

Blokker and van Hoorn (1959) built upon Van Oort's investigation of the aging of asphalt in the dark. Whereas Van oort concluded that the extent of aging would be limited by diffusion to $7 \mu \mathrm{m}$, Blokker and van Hoorn demonstrated and substantiated their demonstration with theoretical interpretations that hardening may occur down to depths of $3 \mathrm{~mm}$ or more. Blokker and van Hoorn also increased oxygen pressure to accelerate the reaction rates. Depending upon the order of reaction in the reaction rate equation, the concentration of oxygen in the atmosphere can also affect the reaction rate substantially.

Blokker and van Hoorn's experiments showed that $\mathrm{n}$ in the reaction rate equation was 0.6. This relationship indicates that the concentration of oxygen can be instrumental in affecting the aging rates of asphalt. Blokker and van Hoorn also found that the activation energy, the temperature dependence coefficient of the reaction rate constant, was $12 \mathrm{kcal} / \mathrm{mole}$ instead of the 
$24 \mathrm{kcal} / \mathrm{mole}$ measured by Van 0ort. At this new activation energy, a $10^{\circ} \mathrm{C}$ rise over ambient will approximately double the reaction rate, still making temperature a good acceleration parameter. Based on Blokker and van Hoorn's data, temperature and partial pressure of oxygen were selected as the aging parameters for the PNL liner evaluation study.

To obtain the equivalent of 1000 years of aging in a 3-month period, it was necessary to accelerate the reaction rate by a factor of 4000 . Since temperature and oxygen alone were not anticipated to accelerate the aging reactions to the equivalent of 1000 years, another accelerated aging parameter was sought. Since most of the uranium mill tailings leachates have considerable oxidizing agents, such as sulfates, we speculated that increasing the strength of these oxidizing agents would increase the rate of chemical degradation. Basic chemistry shows that the concentration of hydrogen ions can increase the oxidizing strength of sulfate. Therefore, by increasing the hydrogen ion content in simulated leachate from a nominal $\mathrm{pH}$ of 2.5 to lower $\mathrm{pH}$ values, the oxidizing strength of sulfates and other oxidizing agents would potentially be increased. Thus, three accelerated aging parameters were identified for the uranium mill tailings liner evaluation. They include temperature, oxygen partial pressure, and acidity controlled by $\mathrm{pH}$.

\section{EXPOSURE COLUMNS}

Barnes and Buelt (1982) have previously described the 0.6-m dia exposure columns used to subject the asphalt liner membranes to simulated mill tailings impoundment conditions. These larger diameter columns more accurately simulate field conditions while still maintaining a controlled environment. The column, depicted in Figure 2, was constructed in two parts from carbon steel pipe and flanges with internal epoxy coatings to inhibit reactions with low pH leachates. The asphalt liner was poured over a foundation soil where the two portions of the column were joined. A subsidence bladder designed to duplicate physical stresses expected in the field during foundation soil subsidence is located directly beneath the liner in the foundation soil. The subsidence bladder is constructed of two sealed chlorosulfanated polyethylene membranes filled with water that can be removed during liner exposure. This causes 


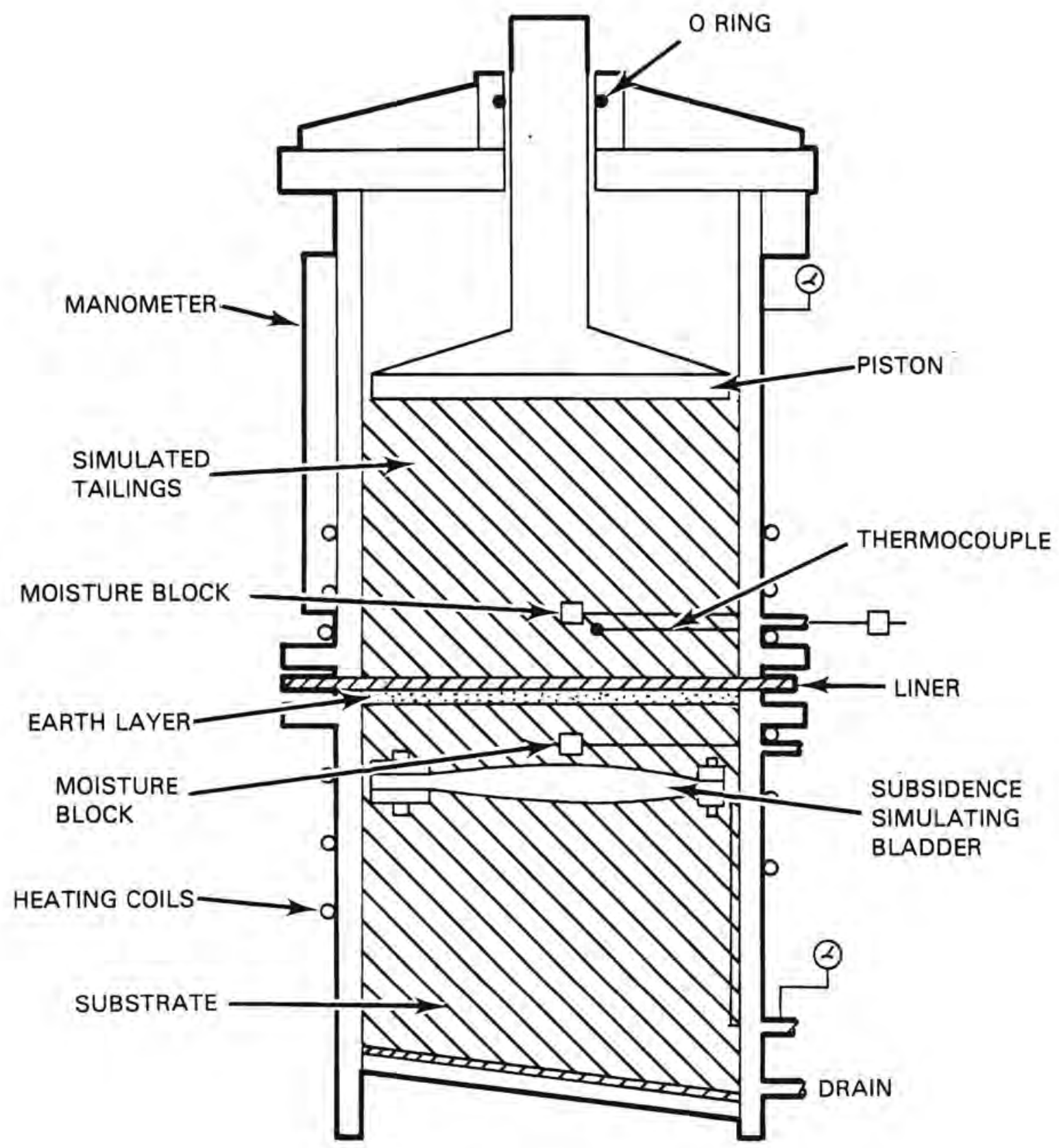

FIGURE 2. Exposure Column

the bladder to collapse, subjecting the liner to the same physical stresses incurred from a subsidence of $1 \mathrm{~cm}$ per $10 \mathrm{~cm}$ of length. Above the liner, specific yradations of sand were added to simulate uranium mill tailings. A hydraulic piston continually exerts a force on the sand simulating the weight of $6 \mathrm{~m}$ of tailings above the liner. Together, the subsidence bladder and 
piston above the simulated tailings duplicate the compressive and tensile stresses expected in the field and indicate the extent of impregnation of sand particles into the liner at accelerated temperatures.

Simulated tailings leachate, the composition shown in Table 1, was added to the sand. The columns were then sealed above the liner so that a pressurized atmosphere could be subjected to the liner. This not only increases the partial pressure of oxygen necessary for accelerating asphalt aging, but also forces limited quantities of leachate through the liner for better permeability measurement during the exposure period. The higher hydrostatic head also helps force leachate through the liner, thereby eliminating diffusion-controlled reactions.

The entire exposure column is surrounded by heating/cooling coils within $5 \mathrm{~cm}$ of high-quality insulation. The heating/cooling coils subject a controlled temperature to the entire exposure column. As discussed earlier, temperature is one of the parameters used for the accelerated aging tests.

\section{EXPOSURE CONDITIONS}

Because of the sophisticated design of these columns, it is desirable to linit the number of exposure conditions. However, to determine the influence

TABLE 1. Simulated Tailings Leachate Composition

\begin{tabular}{|c|c|}
\hline Chemical & Concentration, $\mathrm{g} / \mathrm{e}$ \\
\hline $\mathrm{CaSO}_{4}$ & 500.0 \\
\hline $\mathrm{CaCO}_{3}$ & 18.1 \\
\hline $\mathrm{MgSO}_{4}$ & 8.6 \\
\hline $\mathrm{Na}_{2} \mathrm{SO}_{4}$ & 7.4 \\
\hline $\mathrm{NaCl}$ & 7.4 \\
\hline $\mathrm{Fe}_{2} \mathrm{O}_{3}$ & 2.4 \\
\hline $\mathrm{NaCO}_{3}$ & 2.3 \\
\hline $\mathrm{AT}_{2} \mathrm{O}_{3}$ & 1.2 \\
\hline
\end{tabular}


of each parameter on aging reactions, variable exposure conditions must be imposed. Selecting three values for each of the three parameters require a $3 \times 3 \times 3$ testing matrix, resulting in 27 exposure tests for the liner. Since only eight exposure columns were available, a statistical method for selecting only key parameter combinations in the $3 \times 3 \times 3$ matrix was employed for testing. The statistical method, known as the fractional factorial matrix, requires measurements at only 11 points, instead of 27 , as shown in Figure 3 . According to this statistical method the high and low values of each parameter are selected for testing. The liner is also subjected to three exposure tests at the intermediate values of all three parameters to obtain a statistical variation of the data. With eight exposure columns being available, the eleven measurements could be made in two series of tests leaving spares to rerun any cases that might be indicated.

The temperature was controlled for the various points on the fractional factorial matrix with three glycol circuits. The intermediate and high
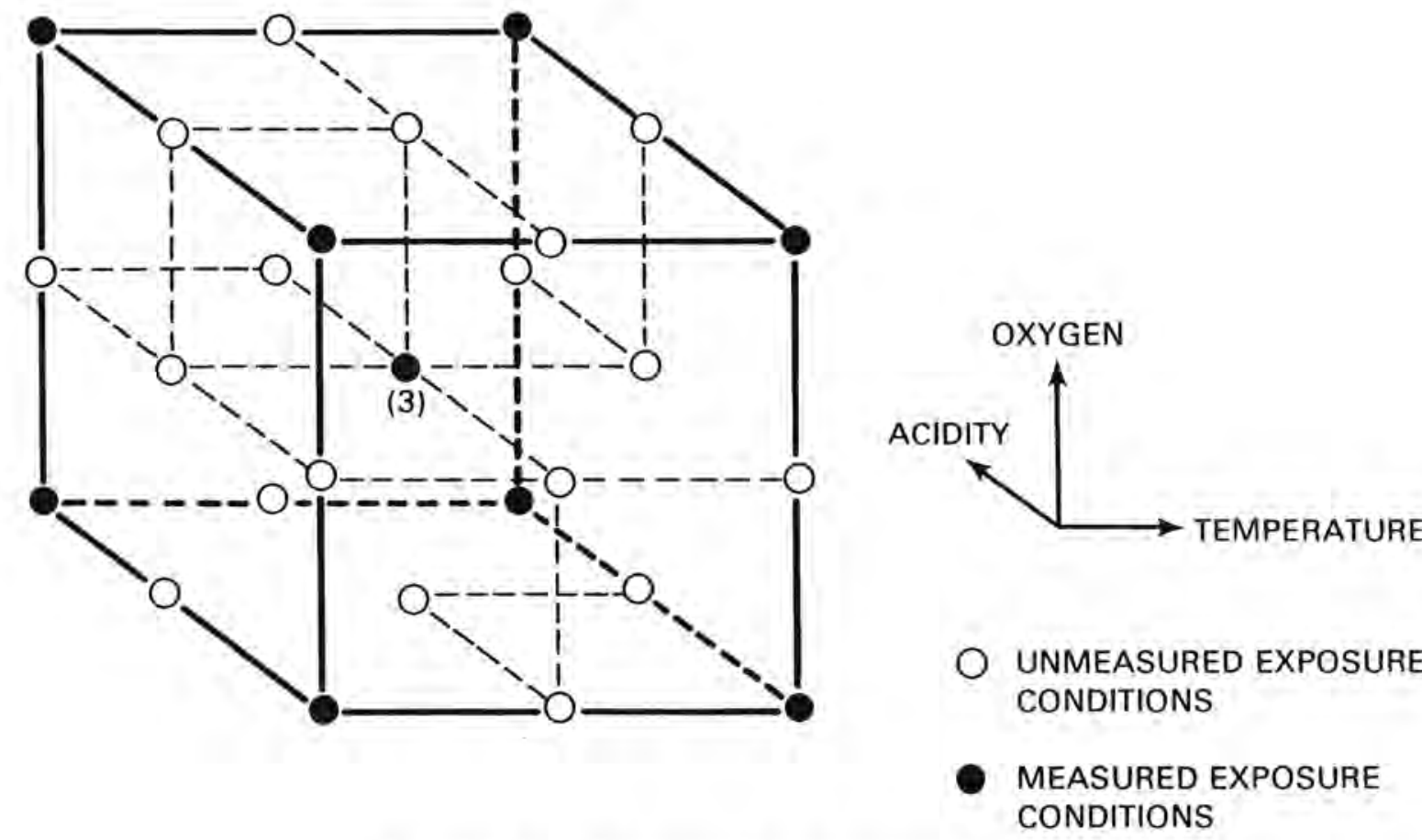

FIGURE 3. Fractional Factorial Matrix 
temperatures, 35 and $50^{\circ} \mathrm{C}$, were maintained by electrical heaters immersed in glycol that is continually recirculated through the heat transfer coils of the respective column(s). The intermediate and high temperature cases were selected on the basis of anticipated reaction rate constants, and the desire to avoid chemical reactions above $50^{\circ} \mathrm{C}$ that might not normally occur. The $20^{\circ} \mathrm{C}$ ambient temperature was maintained in the column by use of a heat pump. This temperature represents the equivalent ground temperature that might be expected below a uranium mill tailings pile.

The range of oxygen partial pressures for accelerated aging was based on ambient conditions, the maximum pressure rating of the exposure column, and an arithmetic average between the two. Therefore, $0.21 \mathrm{~atm}, 1 \mathrm{~atm}$, and $1.7 \mathrm{~atm}$ were selected as the exposed oxygen partial pressure with a total pressure of $1.7 \mathrm{~atm}$ in all cases. The prescribed partial pressure of oxygen was maintained in the exposure column by two flow control valves from oxygen and nitrogen supply tanks. The intermediate and ambient oxygen partial pressures were more difficult to maintain since the flow of oxygen and nitrogen had to be balanced to match the leak rate of the exposure columns.

The acidity levels were maintained by periodic sampling of the leachate directly above the liner. As the pH slowly increased throughout the exposure period, additional sulfuric acid was introduced into the exposure column. The $\mathrm{pH}$ tended to increase because the leachate interacted with the exposure column, the simulated tailings, and possibly the asphalt liner itself. This posed a difficult control problem and required that various conditions be rerun in the second series of tests. The base case of $\mathrm{pH}=2.5$ was selected as the lowest measured $\mathrm{pH}$ from a variety of batch leaching samples of uranium mill tailings from Ship Rock, Durango and Salt Lake City. The pH values for the accelerated conditions were selected at 2.0 and 1.5. Subsequent column leaching studies showed that the initial pore volume of leachate passing through Ship Rock tailings has a pH of 1.8 increasing to higher $\mathrm{pH}$ values with subsequent pore volumes of leachate (Relyea and Martin 1982). The concern over maintaining accurate $\mu \mathrm{H}$ levels proved to be inconsequential, however, since it was discovered during asphalt liner analysis that acidity levels have an unineasurable effect on the extent of aging. 
The appendix shows the $\mathrm{pH}$ curves experienced for all asphalt samples throughout both series of tests. Temperature and oxygen exposure conditions are also yiven.

\section{PERMEABILITY}

Permeability, used to measure the immediate effectiveness of the liner, is calculated by the Darcy equation for saturated flow (Hillel 1980):

$$
\mu=\frac{\dot{V} \cdot x}{A \cdot P}
$$

where:

$$
\begin{aligned}
& u=\text { permeability coefficient }(\mathrm{cm} / \mathrm{s}) \\
& \dot{V}=\text { the volumetric flow rate through the liner }\left(\mathrm{cm}^{3} / \mathrm{s}\right) \\
& X=1 \text { iner thickness }(\mathrm{cm}) \\
& A=\text { exposed surface area }\left(\mathrm{cm}^{2}\right) \\
& P=\text { hydrostatic pressure }\left(\mathrm{cm}-\mathrm{H}_{2} \mathrm{O}\right) .
\end{aligned}
$$

The exposure column's manometer measures leachate level in the column. Readings collected over a given period determine the volumetric flow rate of leachate passiny through the liner. Thus, the permeability of each asphalt liner was determined during the exposure period by changes in manometer level. The amount of leachate penetrating the liner, if sufficient, could be collected in the botton drain of the exposure column and be averaged over the time period between collection periods for a redundant measurement. However, because of the low permeability of the asphalt liner $\left(10^{-9}-10^{-10} \mathrm{~cm} / \mathrm{s}\right)$, ineasurable volumes of leachate were rarely collected. The required time period for a perileability measurement was approximately 2 weeks as indicated by the manometer.

Because of the chemical durability of the asphalt, accelerated aging conditions produced no measurable effect on permeability with time, even after the subsidence bladder was collapsed. Figure 4 represents the permeability measurements for three liners at normal, intermediate and highly accelerated conditions. Because of the flatness of the curves, the figure indicates that 


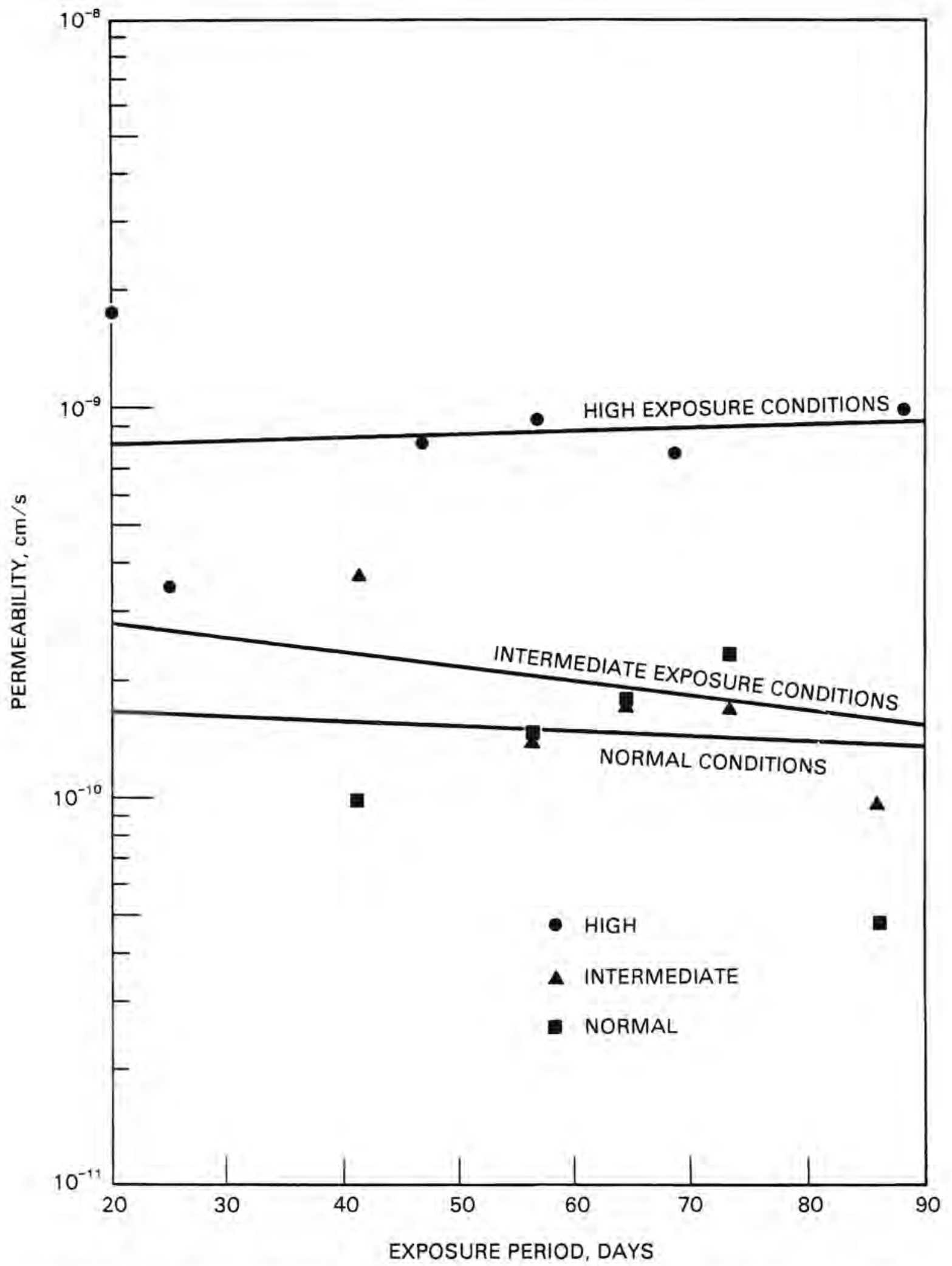

FIGURE 4. Permeability of Asphalt Liner at Normal and Intermediate and Highly Accelerated Conditions 
pernieability cannot be used to determine the extent of aging in the asphalt liner and that additional analytical techniques are necessary to make that determination. However, the permeability curves do indicate that, even for the maximum accelerated aging conditions, the performance of the asphalt liner is not affected. Permeability data for each of the runs is given in the appendix.

ANALYTICAL RESULTS

Since permeability was not a good measure of the extent of aging, the formation of reaction products was analyzed as a function of depth into the liner. This helped determine whether aging is a near surface phenomenon or whether it extends well into the depth of the asphalt. The asphalt membrane was, therefore, sampled in $4 \mu \mathrm{m}$ increments using a microtome. Microtoming is normally used for obtaining thin biomedical samples for analys is of animal tissue. To adapt microtoming for the asphalt study, special casting techniques of the asphalt sample in Paraplast ${ }^{\circledR}$ (paraffin wax) or O.C.T. ${ }^{\circledR}$ were used.

The andytical technique selected for determining the extent of aging was infrared spectrometry. The infrared spectrometric method tells how much of the asphalt has been converted to carbonyl forms, the product of aging. The formation of carbonyls is important in the asphalt process because they are polar groups that form at the end of a hydrocarbon chain. These polar, oxygencontaininy groujs sometimes combine with other hydrocarbon chains, increasing the hiyher molecular weight fraction in the asphalt. This increases the viscosity and brittle nature of the asphalt nembrane. Experience with the infrared spectronetric method showed that all of the asphalt samples at various depths could be analyzed cost-effectively by this technique.

Separate infrared analysis of Paraplast and asphalt showed that the absorption bands for these two materials are very similar. Their similarity was not discovered until after the first series of tests had been cast and

(- Paraplast is a registered trademark of the Lancer Division of Snerwood Medical, St. L.ouis, Missouri.

(20) 0.C.T. (Optimal Cutting Temperature) is a registered trademark of the Labtek Division of Myles Laboratory, Naperville, 111 inois. 
microtomed for analysis. Therefore, the second series of asphalt samples were cast in 0.C.T., a material whose absorption bands differed significantly from asphalt. Figure 5 shows the absorption bands with their associated contributors for each of these materials. The carbonyl absorption band falls within the 1667 to 1800 wavenumber range. The peak at 1600 wavenumbers is associated with $\mathrm{C}=\mathrm{C}$ bonds from which carbonyls form.

The reaction rates for each sample are determined in the following manner. The contributions of the Paraplast or 0.C.T. to the absorption spectra are first subtracted from the absorption band to obtain the true curve for the asphalt sample. Then, the aging reaction rates are determined by comparing the integrated values of these asphalt absorption curves related to various exposure conditions. The integrated absorption curves for each exposure condition are listed as a function of penetration into the liner, as shown in the appendix. The reaction rate at each depth is determined by rate of formation of carbonyls during the exposure period. It can be expressed by the equation:

$$
R=\frac{C_{C=0}\left|f-C_{C=0}\right|_{i}}{t}
$$

where:

$$
\begin{aligned}
R= & \text { reaction rate } \\
C_{C=\left.0\right|_{f}=} & \text { concentration of carbonyls after exposure, indicated by the } \\
& \text { integrated absorption curve between } 1667 \text { and } 1800 \text { wavenumbers } \\
C_{C=\left.0\right|_{i}=} & \text { initial concentration of carbonyls based on a derived } \\
& \text { relationship with the integrated absorption curve for } \mathrm{C}=\mathrm{C} \\
\mathrm{t}= & \text { exposure time. }
\end{aligned}
$$

Because the influence of the initial concentration of carbonyls was not foreseen, the concentration of carbonyls $\left(\left.C_{C=0}\right|_{i}\right)$ was not measured before exposure. However, a mathematical relationship was derived relating the concentrations of $\mathrm{C}=\mathrm{C}$ which was measured with $\mathrm{C}=0$. The expression was based on emperical data from the three tests in the center of the fractional matrix with 

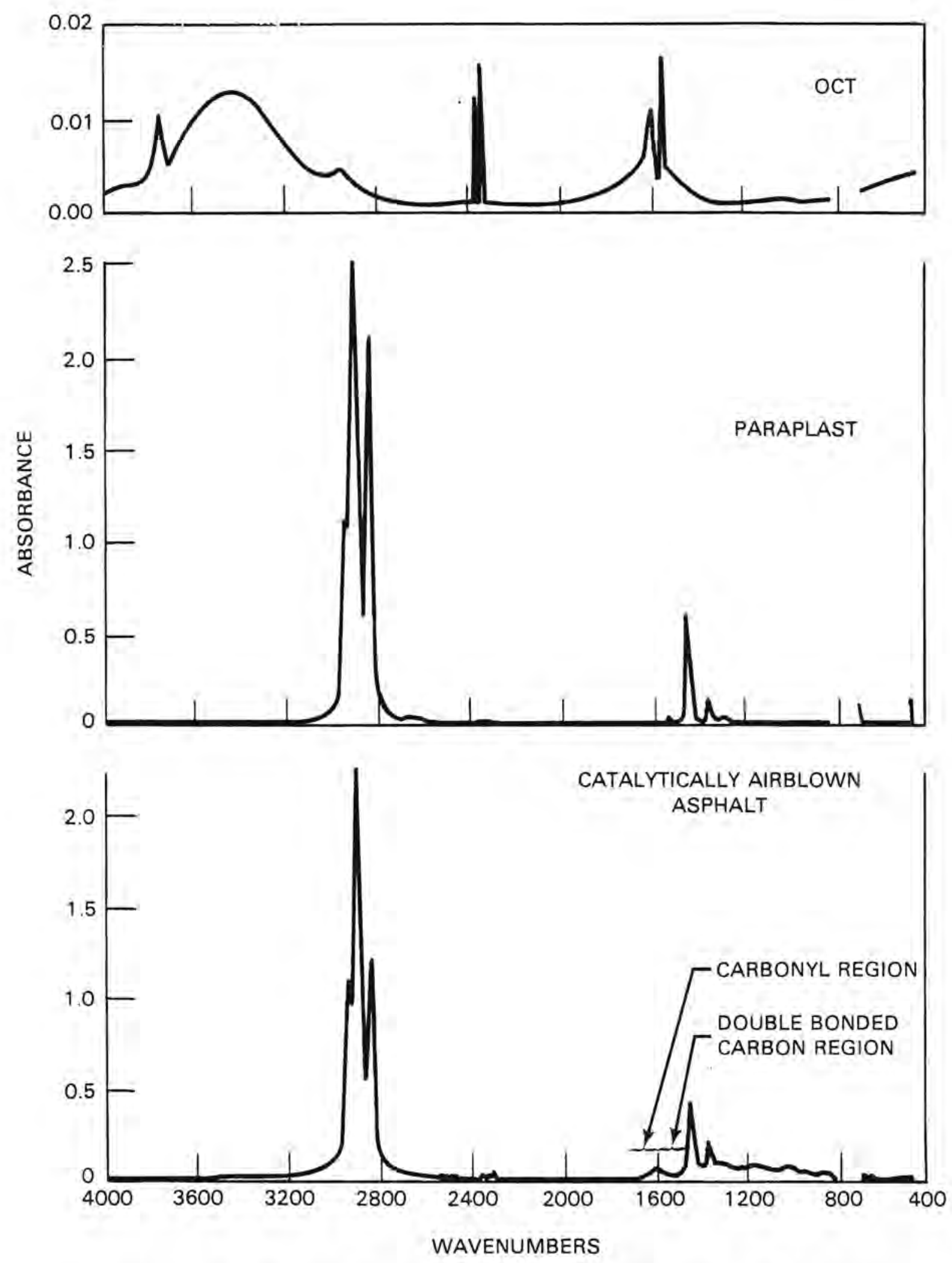

FIGURE 5. Absorption Bands of 0.C.T., Paraplast, and Asphalt 
identical exposure conditions. The reaction rates from Equation 4 were then normalized to their respective, initial concentrations of carbonyls and plotted in Figures $6,7,8$ and 9 for the various exposure conditions. Examination of these plots reveals some important findings:

- temperature and oxygen are effective acceleration parameters

- acidity levels have no measurable effect on aging reactions

- no measurable reaction rate is observed under normal, nonaccelerated conditions

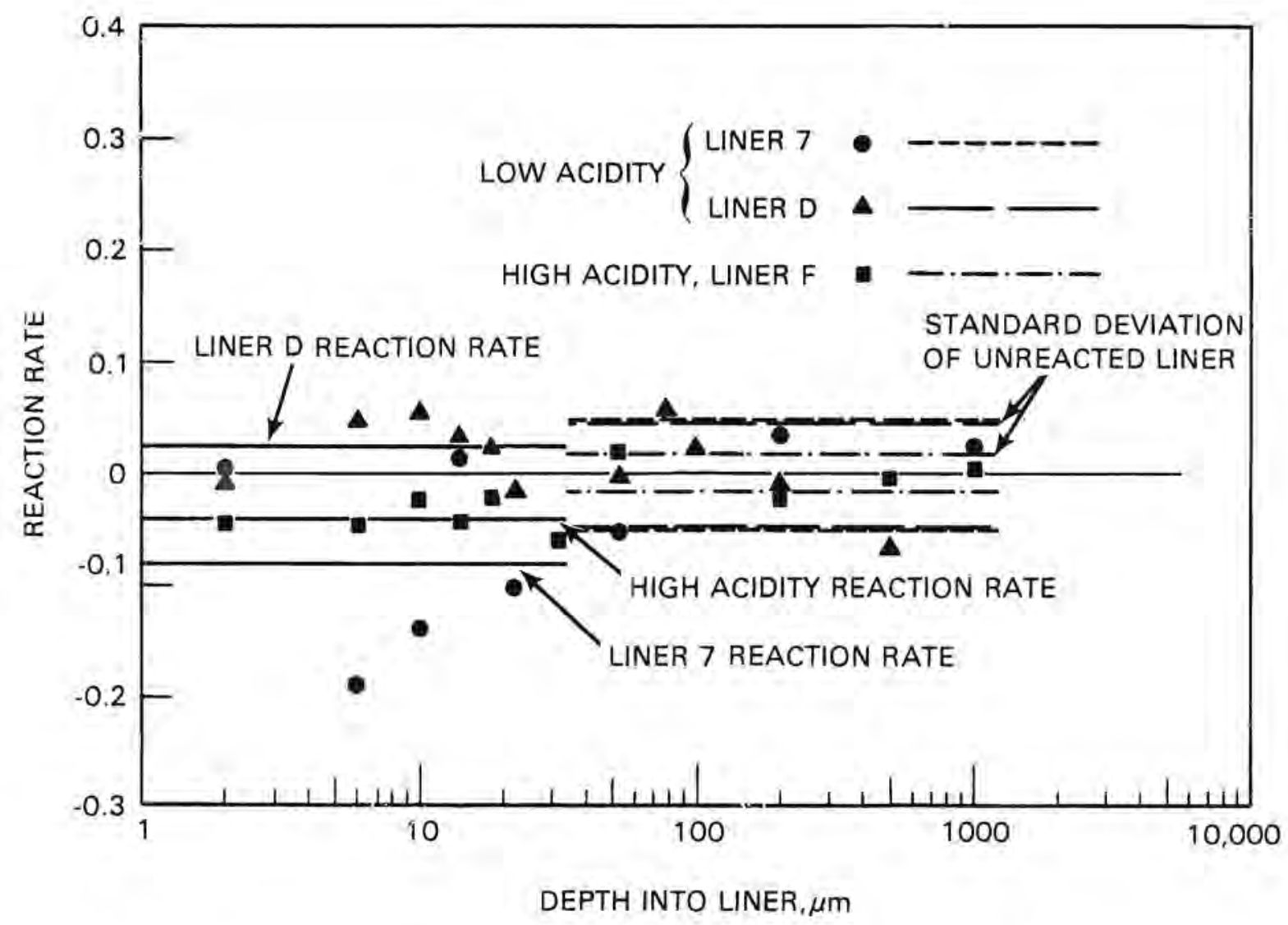

FIGURE 6. Reaction Rates at Normal and Highly Acidic Conditions. Liner designations correspond to data compiled in the appendix 


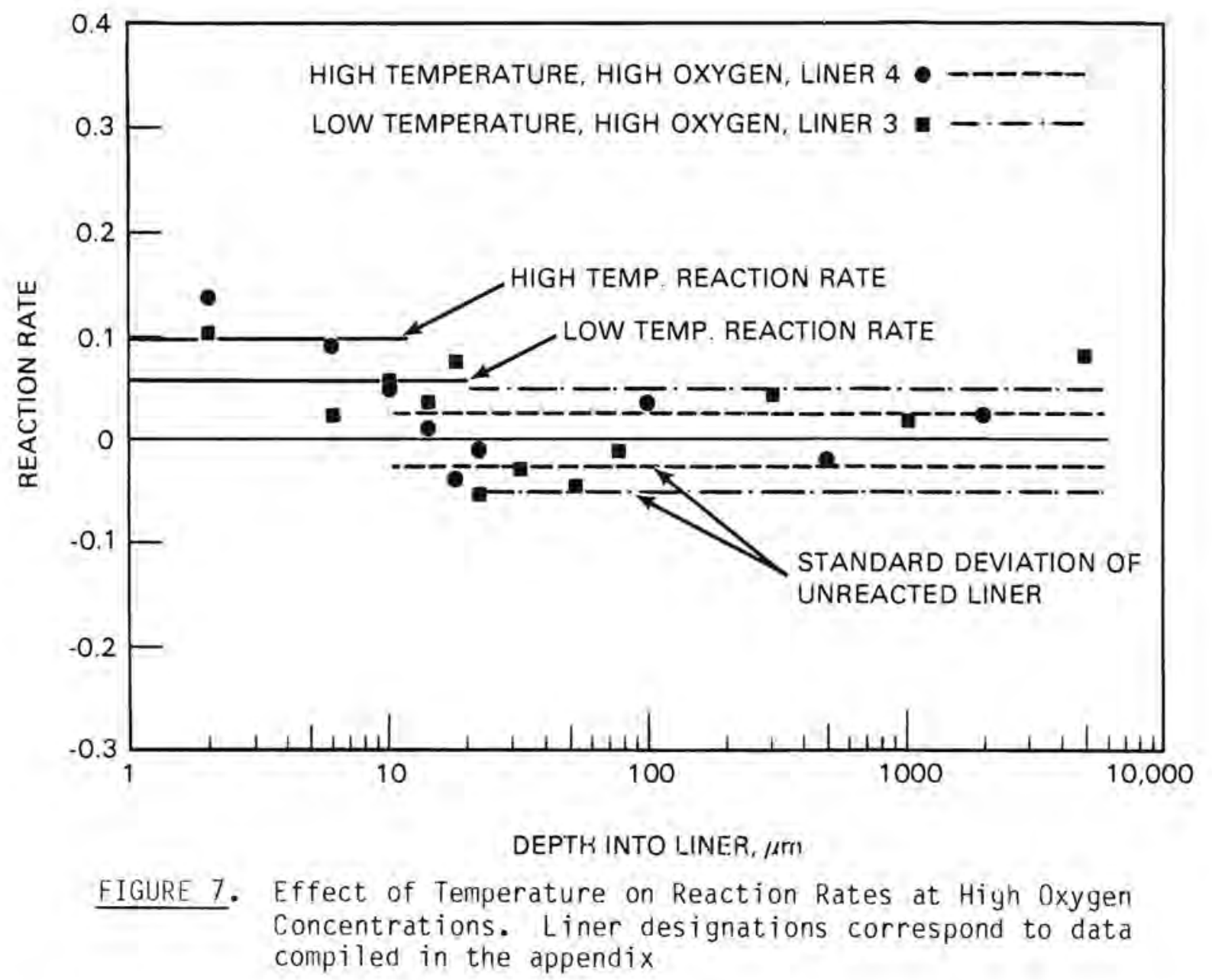

- aying is extremely slow for asphalt, even under accelerated conditions, and

- aging reactions under accelerated conditions penetrate only 10 to $40 \mu \mathrm{m}$.

Let's examine the bases for these conclusions more closely.

The solid horizontal lines shown in Figures 6 through 9 are the arithmetic mean values of the reaction rates measured at the near surface $(10-40 \mu \mathrm{mi})$. The standard deviation of the reaction rates beyond $40 \mu \mathrm{m}$ are then determined separately to help define the bounds of the data scatter. The reaction rate near the surface is considered measurable if the mean value near the surface falls near to or outside the standard deviation at greater depths. 


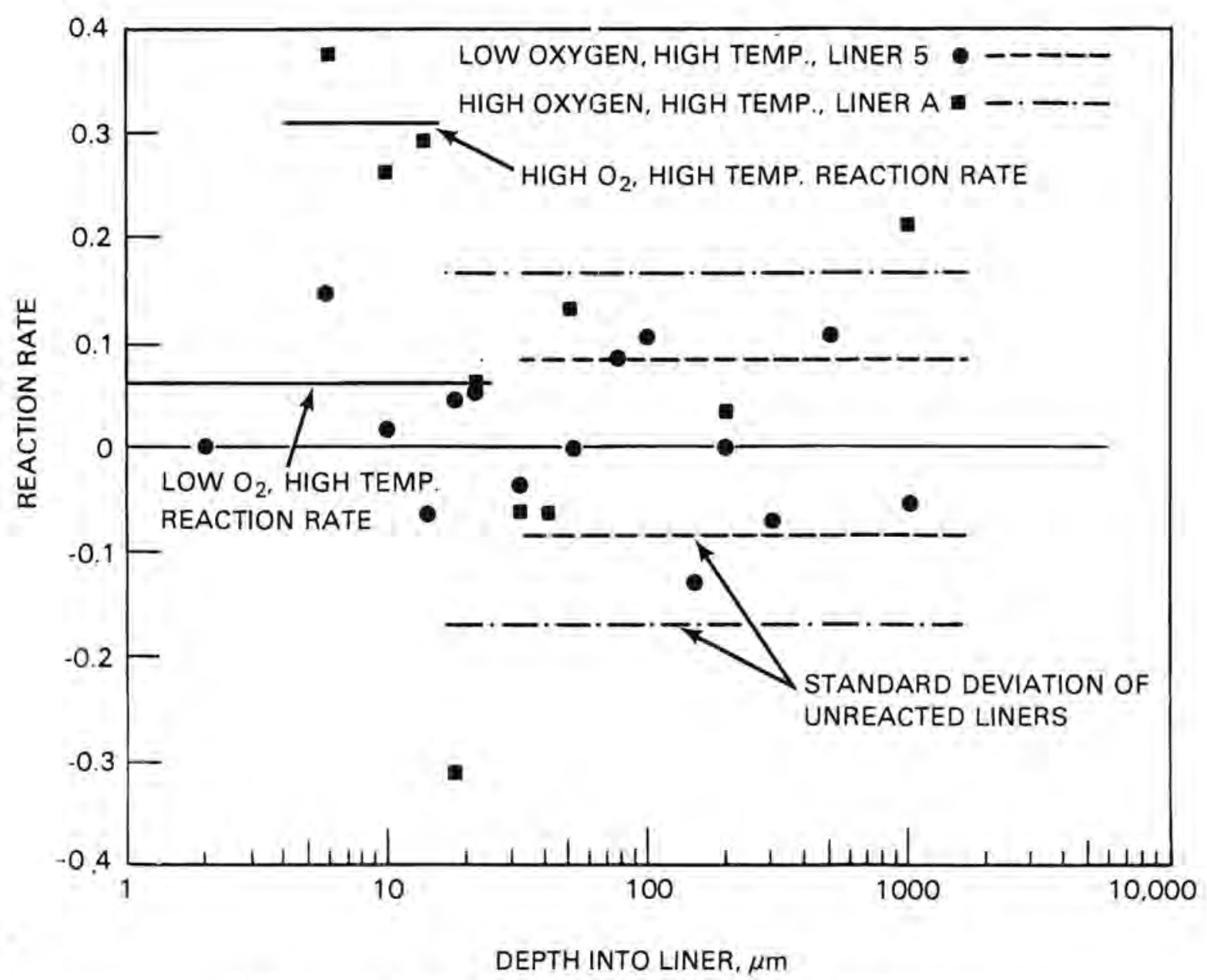

FIGURE 8. Effect of 0xygen on Reaction Rates. Liner designations correspond to data compiled in the appendix

Figure 6 shows two cases conducted at normal exposure conditions and one at high acidity, low temperature and oxygen conditions. No measurable reaction rates are discernible as a function of depth. Thus, we can conclude that aging reactions are not measurable under normal conditions during the 3-month exposure period. Also, increased acidity in the leachate does not accelerate the aging reactions. Apparently the oxidizing nature of sulfuric acid is not a significant degradation mechanism for asphalts.

Figure 7 shows the effect of teriperature on reaction rates for the same oxygen concentrations. The ratio of reaction rates for these two cases is $0.099 / 0.058=1.7$. Comparing the low temperature, high oxygen reaction rate with that in Figure 8 for high temperature, high oxygen conditions results in an increased reaction rate near the surface by a factor of 0.31 (high 


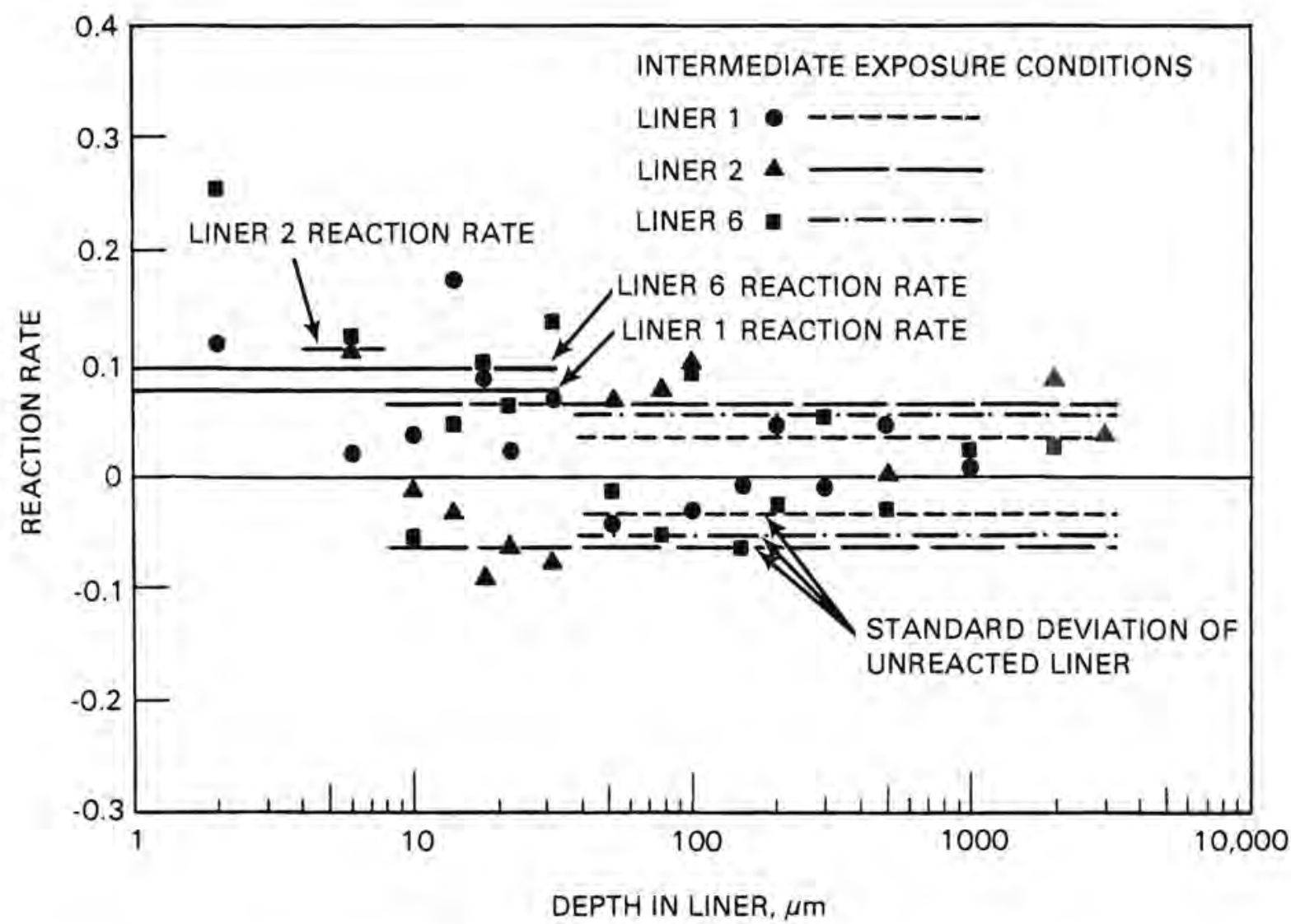

FIGURE 9. Reaction Rates at Intermediate Exposure Conditions. Liner designations correspond to data compiled in the appendix

temperature, high oxygen-Figure 8)/0.058 (10w temperature, high oxygenFigure 7) $=5.3$. Using the higher ratio of reaction rates, the activation energy in Equation (2) can be calculated to be $15 \mathrm{kcal} / \mathrm{g}$-mole. This means that for an increase in temperature of $10^{\circ} \mathrm{C}$, the reaction rate increases by a factor of 2.3. This is consistent with Blokker and van Hoorn's findings in their accelerated aging tests with pavement asphalts.

Figure 8 also shows the effect of oxygen concentration under constant temperature conditions. From this comparison, oxygen evidently has a significant effect on aging. From this plot, the value of $n$ in the reaction rate equation ( 1 ) is calculated to be 0.8 . Blokker and van Hoorn determined $n$ to be 0.6 , so this finding is substantiated. 
The penetration of aging reactions was limited to 10 to $40 \mu \mathrm{m}$ into the surface of the $7000 \mu \mathrm{m}$ thick liner. Blokker and van Hoorn showed that for thick samples, penetration of oxygen as deep as $3000 \mu \mathrm{m}$ might be expected. The discrepancy may be due to the fact that the asphalt liner aging reactions were performed under saturated leachate conditions whereas Blokker and van Hoorn's studies were conducted in air.

Figure 9 shows the reaction rates at the intermediate exposure conditions. The plots substantiate the quantitative effect that temperature and oxygen have on reaction rate. The depth of penetration, 10 to $40 \mu \mathrm{m}$, is also substantiated by these measurements. Even though the data scatter is quite significant, the mean values agree very closely for all three exposed liners. The intermediate exposure results provide an important validation of the accelerated aging methodology and analysis.

\section{PERFORMANCE LIFETIME}

The calculated activation energy $\left(E_{A}\right)$ and dependency of oxygen concentration on reaction rate $(n)$ in the reaction rate equation determine the equivalent exposure period for the maximally exposed liner sample. With a temperature $20^{\circ} \mathrm{C}$ above ambient and $1.7 \mathrm{~atm}$ oxygen partial pressure, the reaction rate was increased by a factor of 30 . This means the equivalent aging period of the liner over 3 months at these conditions was 7 years. The inability of acidity to act as an accelerating aging parameter, and the fact that only $40^{\circ} \mathrm{C}$ was achieved at the accelerated temperature (see appendix), left the equivalent exposure period short of the desired objective. However, because the penetration of aging reactions was minimal, the expected performance lifetime may be extrapolated with some accuracy.

The penetration of the reaction products was only $\sim 14 \mu \mathrm{m}$ at maximum exposure conditions- $-0.2 \%$ of the total liner thickness. Maximum penetration of reaction products was $40 \mu \mathrm{m}$. At the accelerated reaction rate, the time required to penetrate the entire depth of the liner might be increased by a factor of 200 to 500. Based on the aged liner representing 7 years of aging, the asphalt membrane's performance could be expected to greatly exceed the 
1000-year standard. Catalytically airblown asphalt, if needed to prevent groundwater contamination, could therefore be expected to perform extremely well as a leachate barrier at inactive uranium mill tailings piles for long periods. 


\section{REFERENCES}

Barnes, S. M., J. L. Buelt and V. Q. Hale. 1981. Accelerated Aging Tests of Liners for Uranium Mill Tailings Disposal. PNL-4049, Pacific Northwest Laboratory, Richland, Washington.

Barnes, S. M., and J. L. Buelt. 1982. "Accelerated Aging of Catalytical Airblown Asphalt Membranes Under Simulated Uranium Mill Tailings Impoundment Conditions." In Uranium Mill Tailings Management, pp. 433-440. Colorado State University, Fort Collins, Colorado.

Blokker, P. C., and H. van Hoorn. 1959. "Durability of Bitumen in Theory and Practice." Fifth World Petroleum Congress, Section VI, Paper 27, pp. 417-432. New York.

Buelt, J.L., et al. 1981. An Evaluation of Liners for a Uranium Mill Tailings Disposal Site - A Status Report. DOE/UMT-0200, Pacific Northwest Laboratory, Richland, Washington.

Geir, F. H., and W. R. Morrison. 1968. Buried Asphalt Membrane Canal Lining. U.S. Department of Interior Research Report No. 12. Washington, D.C.

Hillel, D. 1980. Fundamentals of Soil Physics. Academic Press, Inc., New York.

Levenspiel, 0. 1972. Chemical Reaction Engineering. John Wiley and Sons, Inc., New York.

Relyea, J.F. 1983. A Decision Tree Approach to Evaluating Inactive Uranium Processing Sites for Liner Requirements. PNL-4436, Pacific Northwest Laboratory, Richland, Washington.

Relyea, J. F., and W. J. Martin. 1982. "Evaluation of Inactive Uranium Mill Tailings Sites for Liner Requirements: Characterization and Interaction of Tailings, Soil, and Liner Materials." Uranium Mill Tailings Management, pp. 507-519. Colorado State University, Fort Collins, Colorado.

Tucker, P. G. 1983. Trench Design and Construction Techniques for Low-Level Radioactive Waste Disposal. NUREG/CR-3144. U.S. Nuclear Regulatory Commission, Washington, D.C.

U.S. Department of Energy. 1982. Annual Status Report on the Uranium Mill Tailings Remedial Action Program. DOE/NE-0025/1, Washington, D.C. 
U.S. Environmental Protection Agency (USEPA). 1983. Standards for Remedial

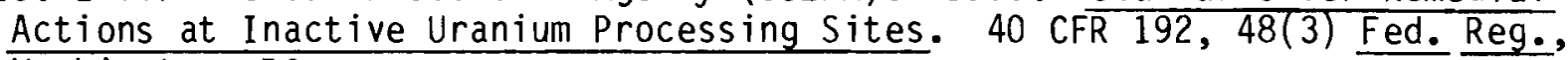
Washington, DC.

Van Dort, W. P. 1956. "Durability of Aspalt - Its Aging in the Dark." Industrial and Engineering Chemistry 58:1196-1201. 


\section{APPENDIX}

EXPOSURE CONDITIONS, PERMEABILITIES, AND REACTION RATES 
APPENDIX

\section{EXPOSURE CONDITIONS, PERMEABILITIES, AND REACTION RATES}

This appendix presents the exposure conditions, permeabilities and the inteyrated infrared absorption band data for the aged liners. Reference codes $A, B$, and $D$ through $G$ refer to the first set of exposure tests. Codes 1 through 7 refer to the second set of exposure tests; and Code $Z$ is the control, unexposed asphalt. 

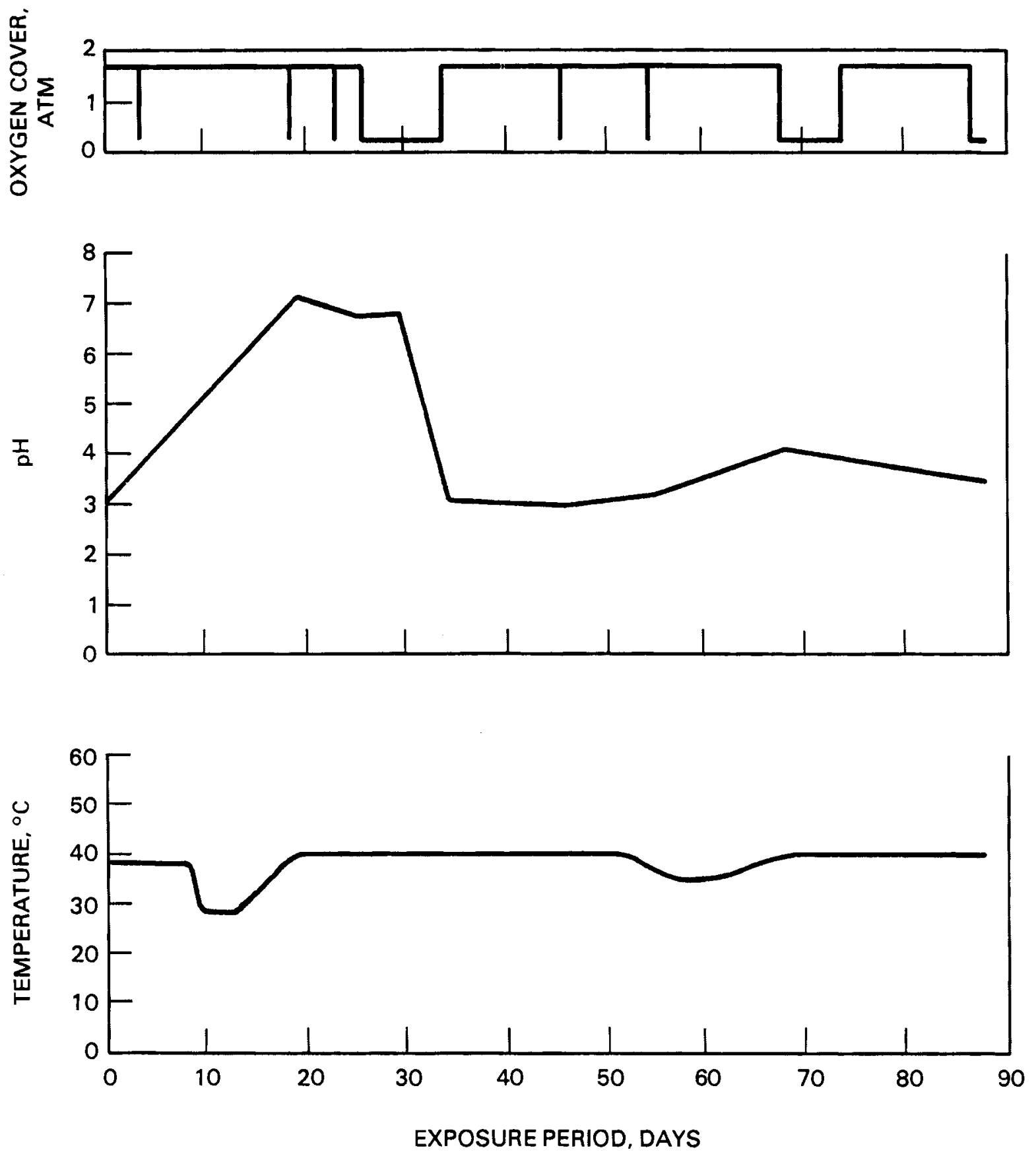

FIGURE A.1. Exposure Conditions for Liner A 

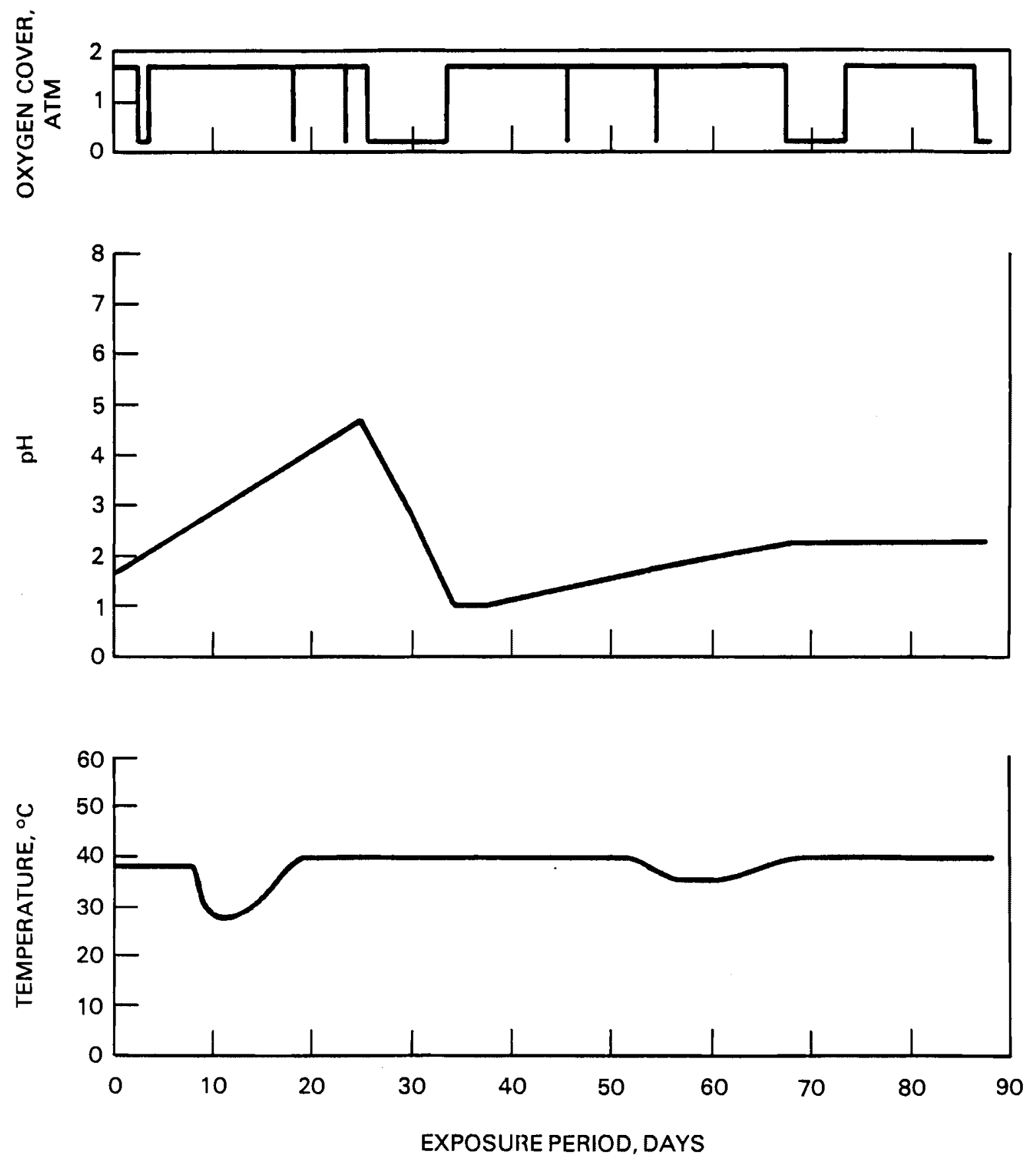

FIGURE A.2. Exposure Conditions for Liner B 

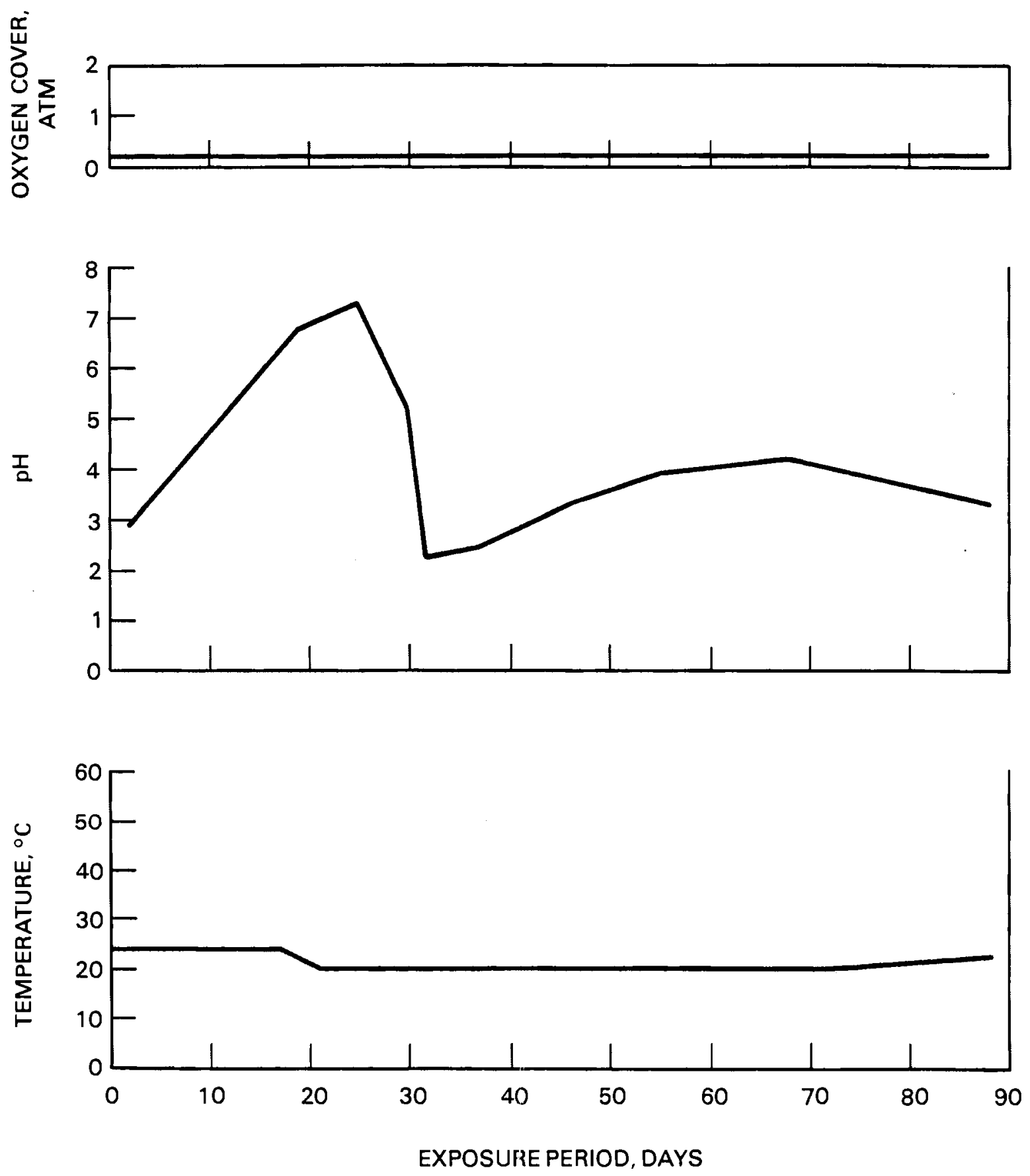

FIGURE A.3. Exposure Conditions for Liner D 

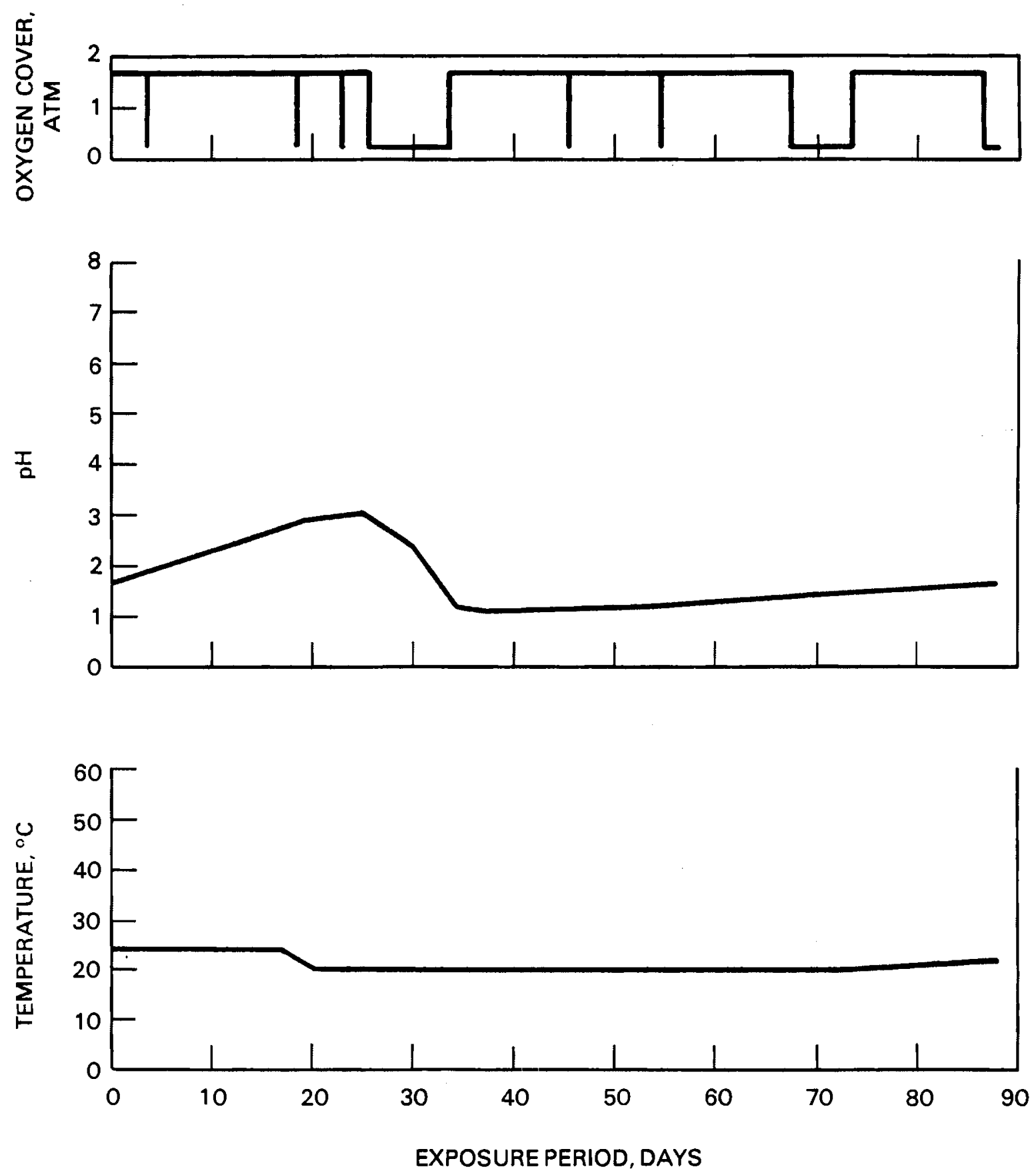

FIGURE A.4. Exposure Conditions for Liner $E$ 

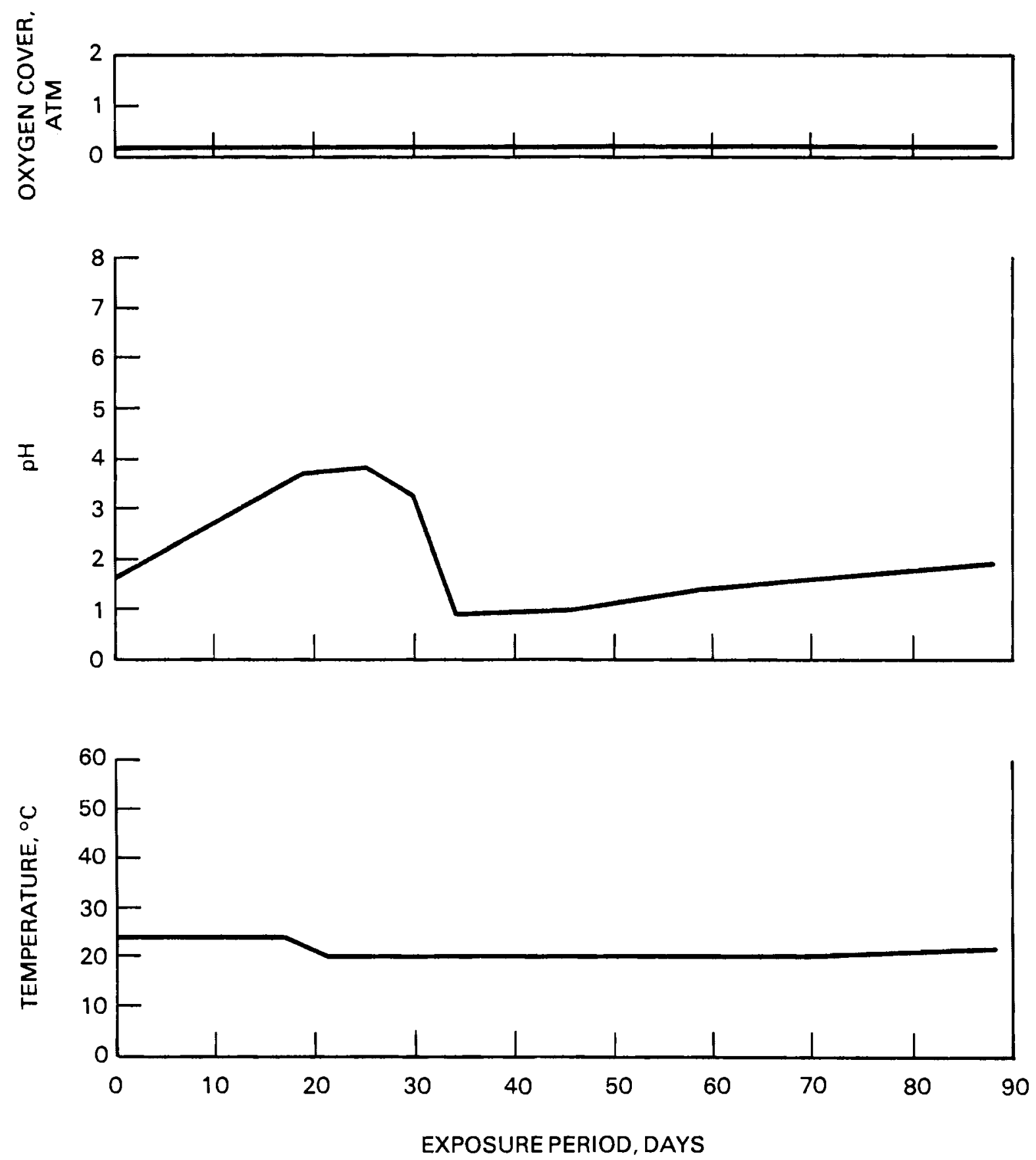

FIGURE A.5. Exposure Conditions for Liner $F$ 

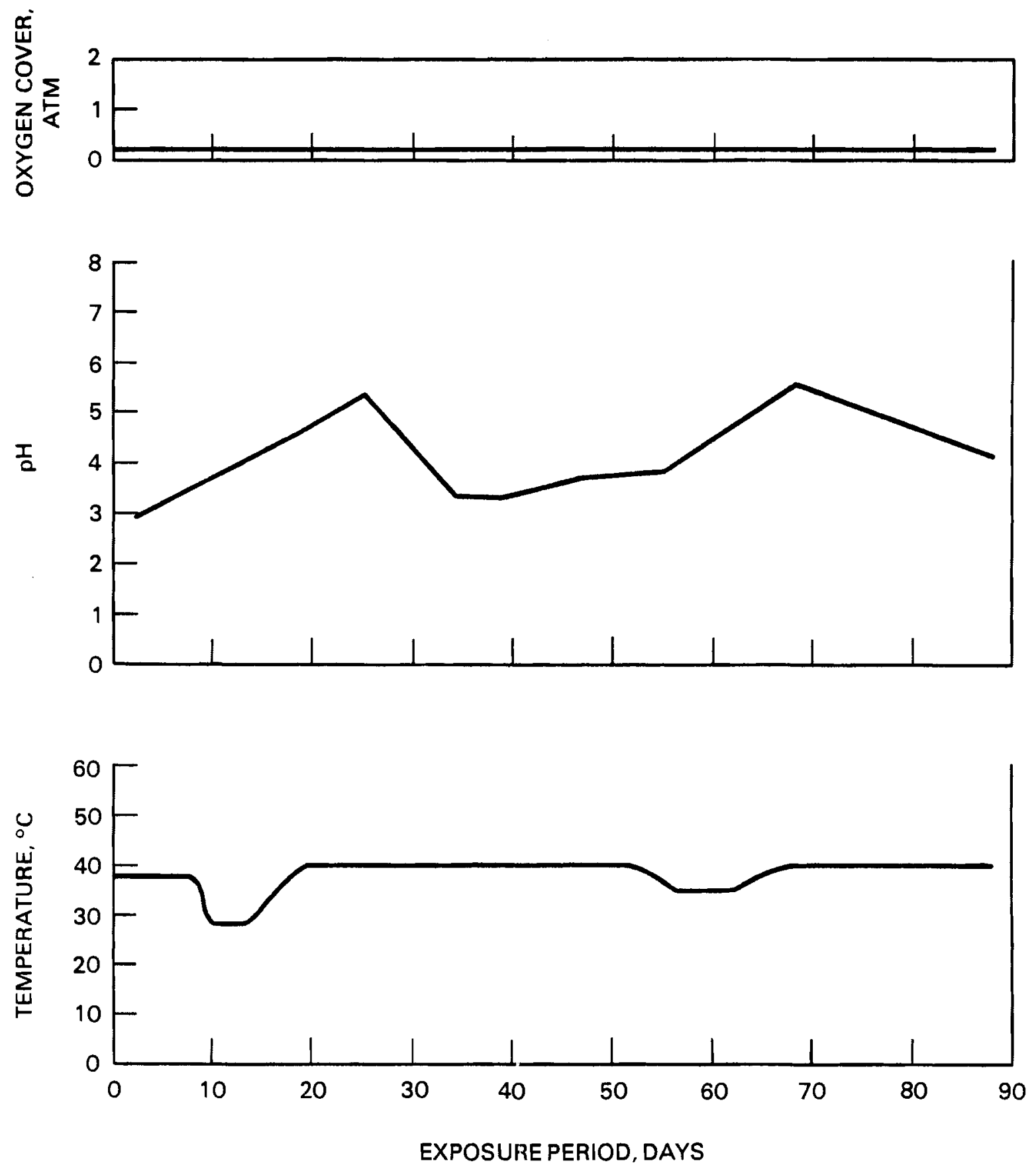

FIGURE A.6. Exposure Conditions for Liner $G$ 

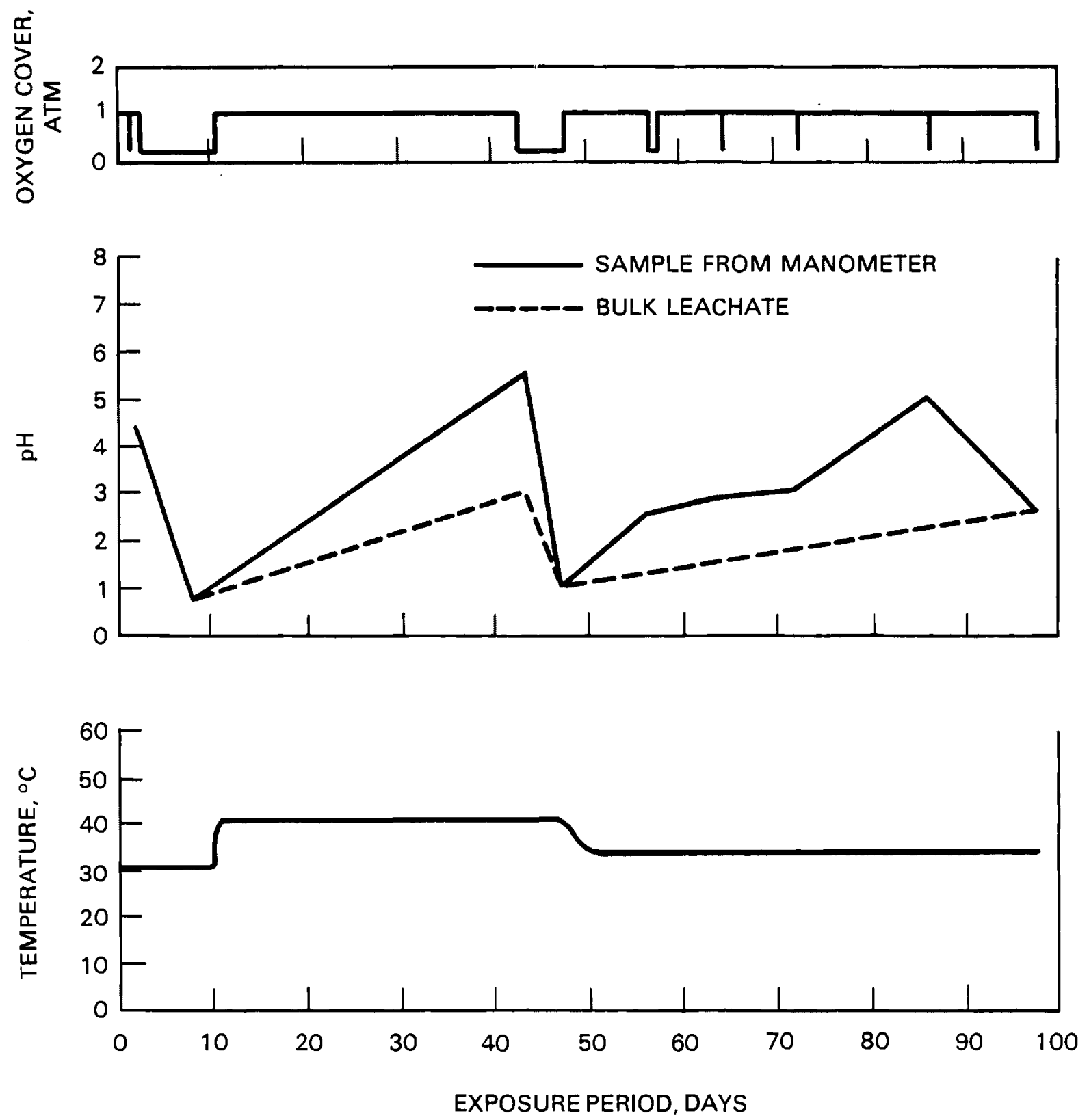

FIGURE A.7. Fxposure Conditions for Liner 1 

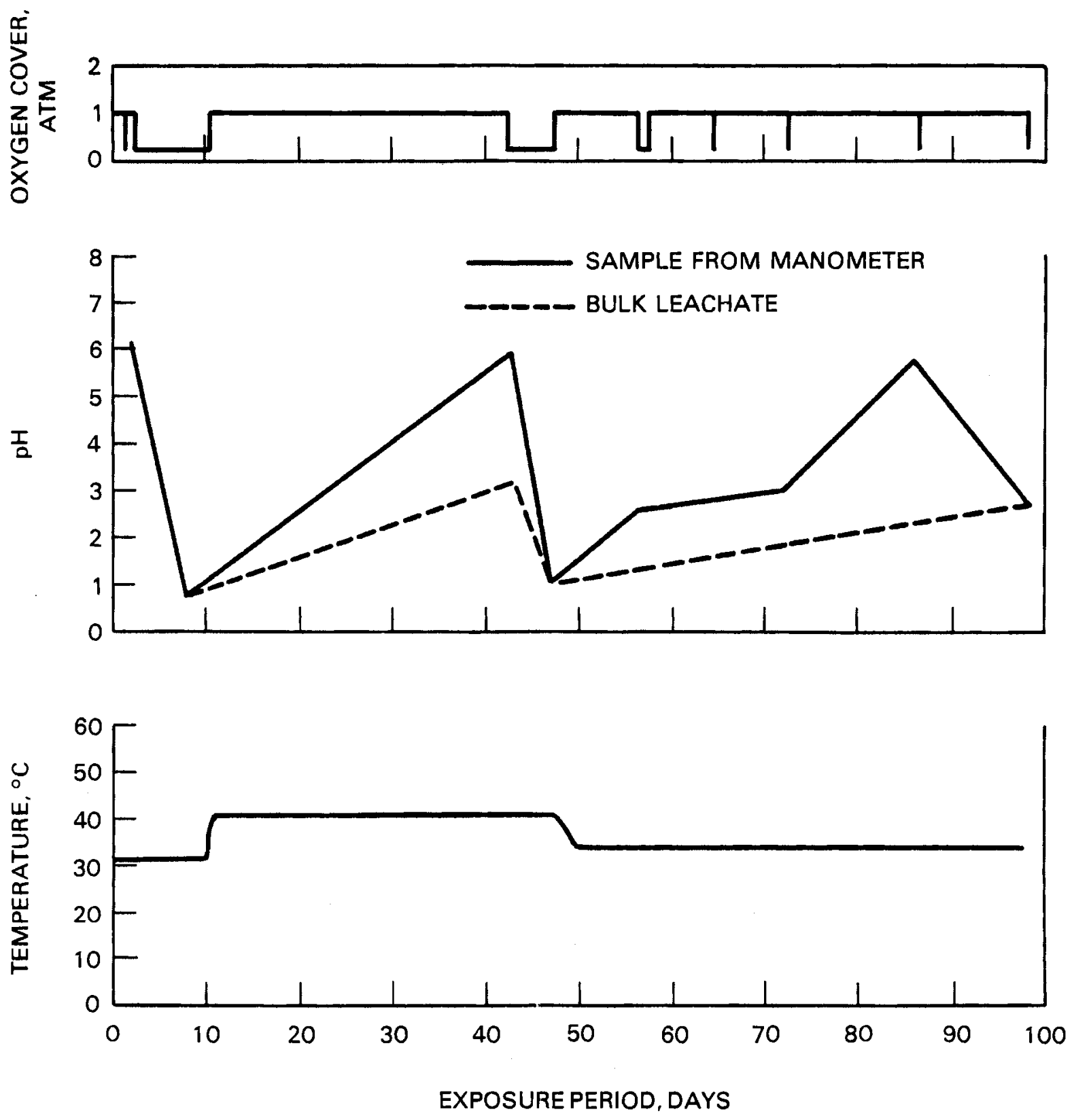

FIGURE A.8. Exposure Conditions for Liner 2 

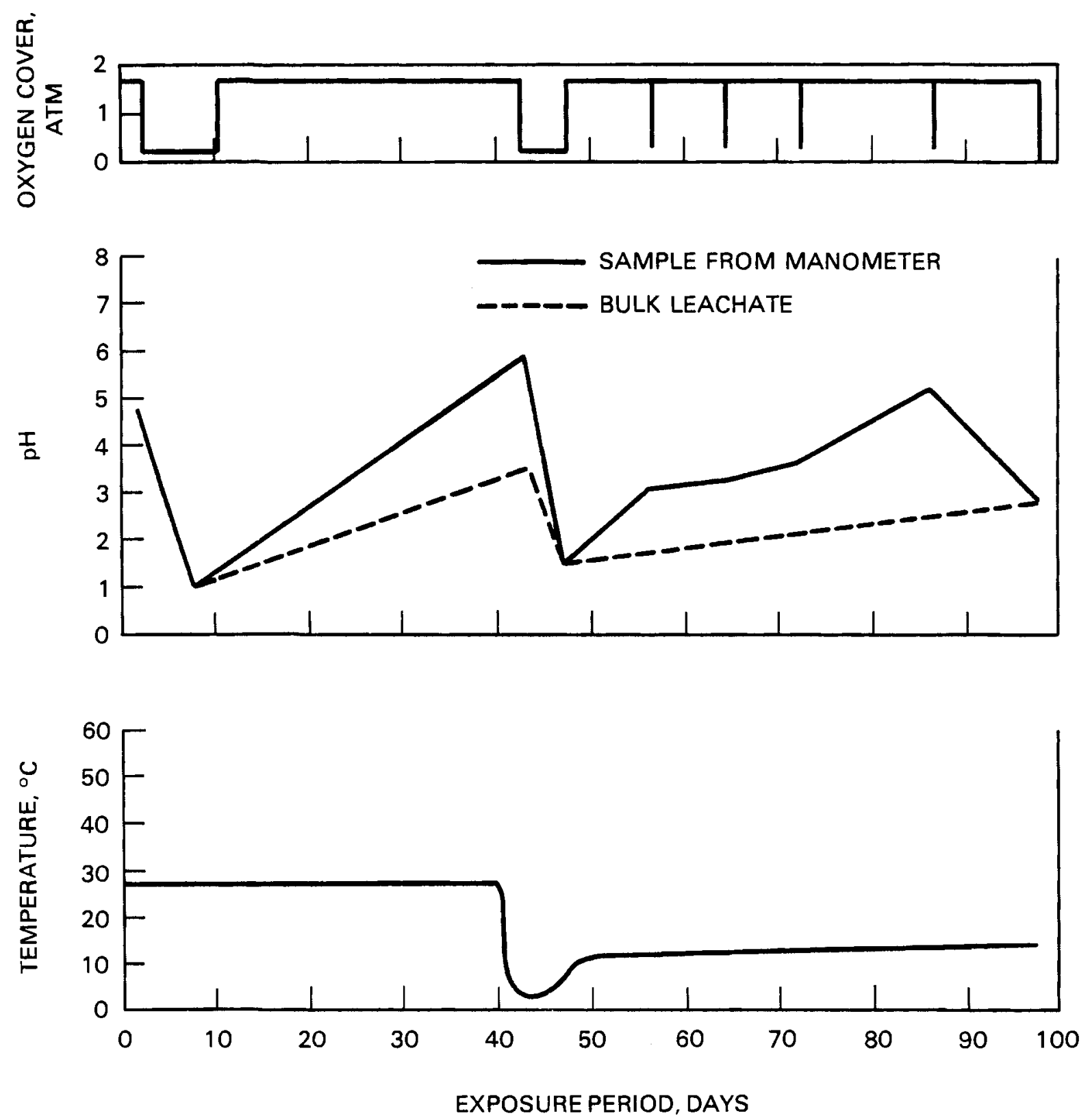

FIGURE A.9. Exposure Conditions for Liner 3 

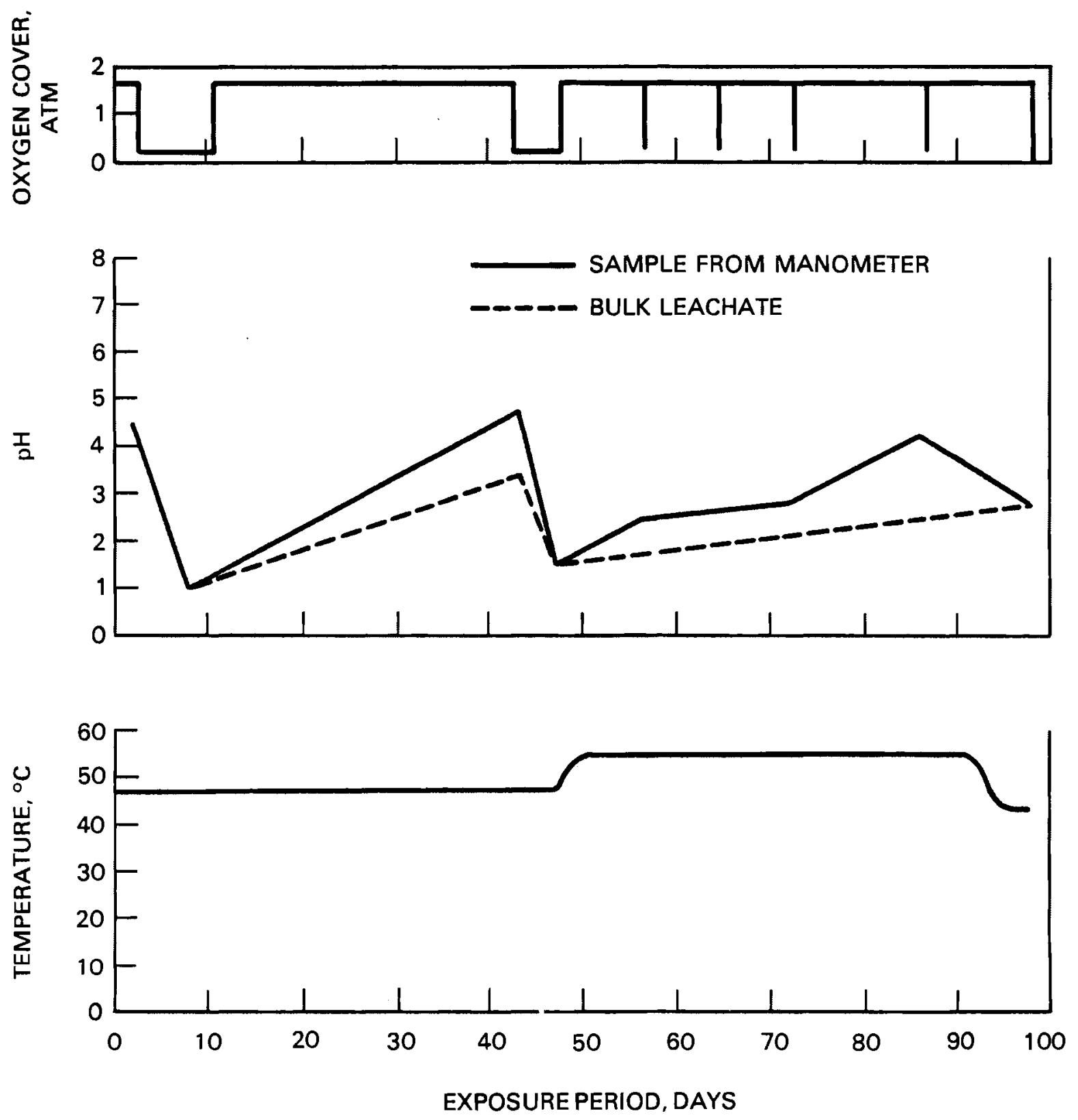

FIGURE A.10. Exposure Conditions for Liner 4 

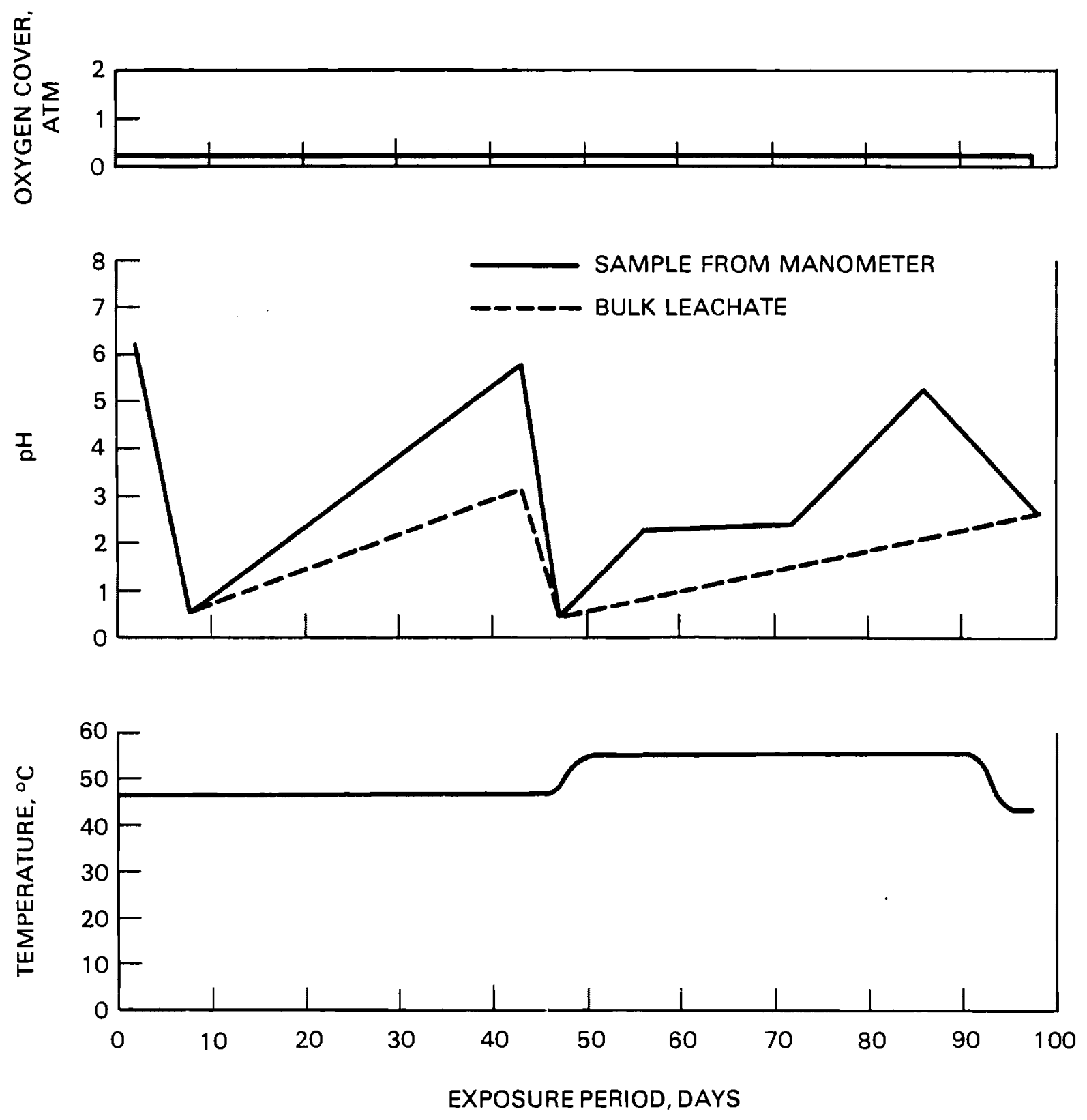

FIGURE A.11. Exposure Conditions for Liner 5 

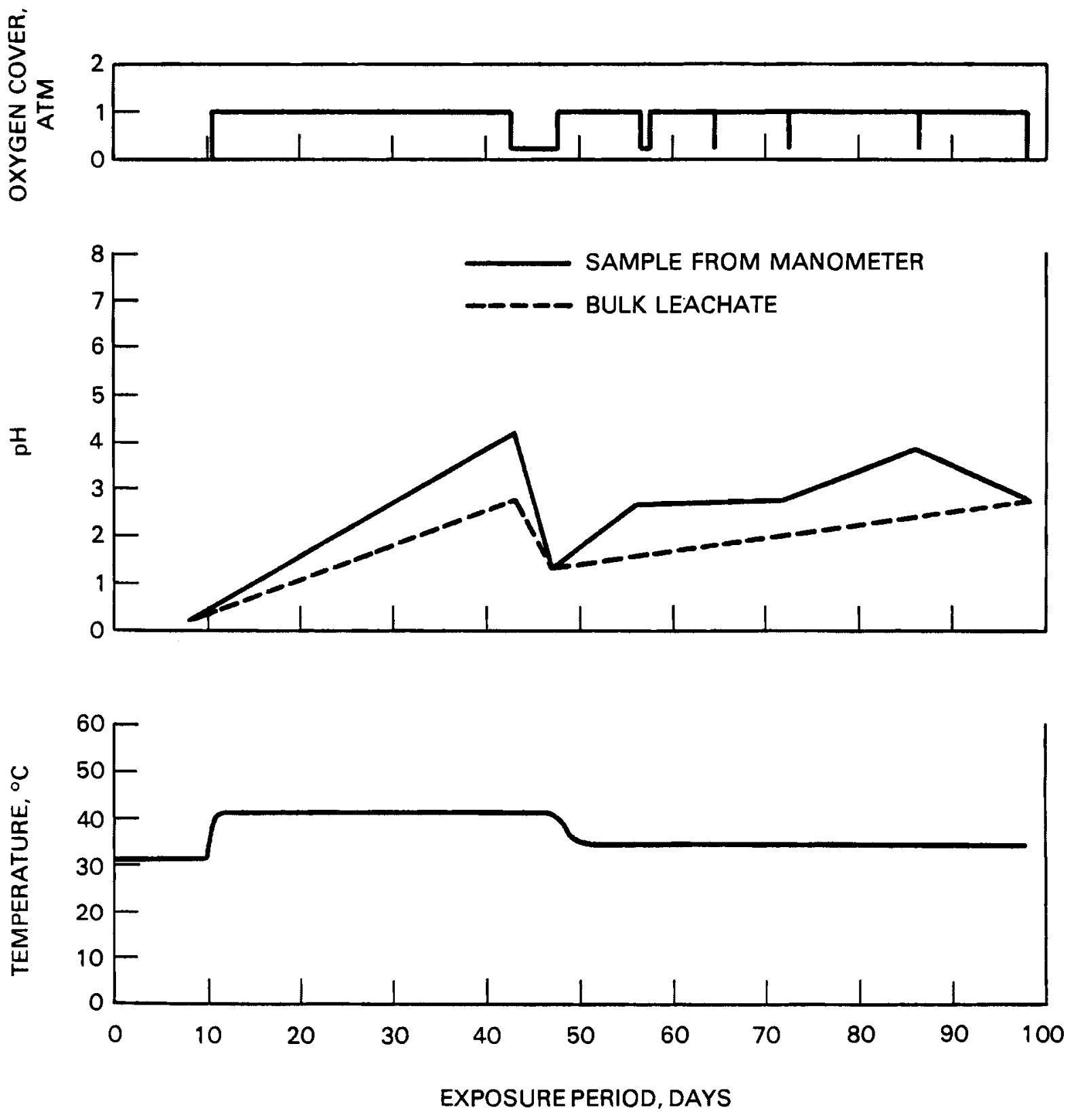

FIGURE A.12. Exposure Conditions for Liner 6 

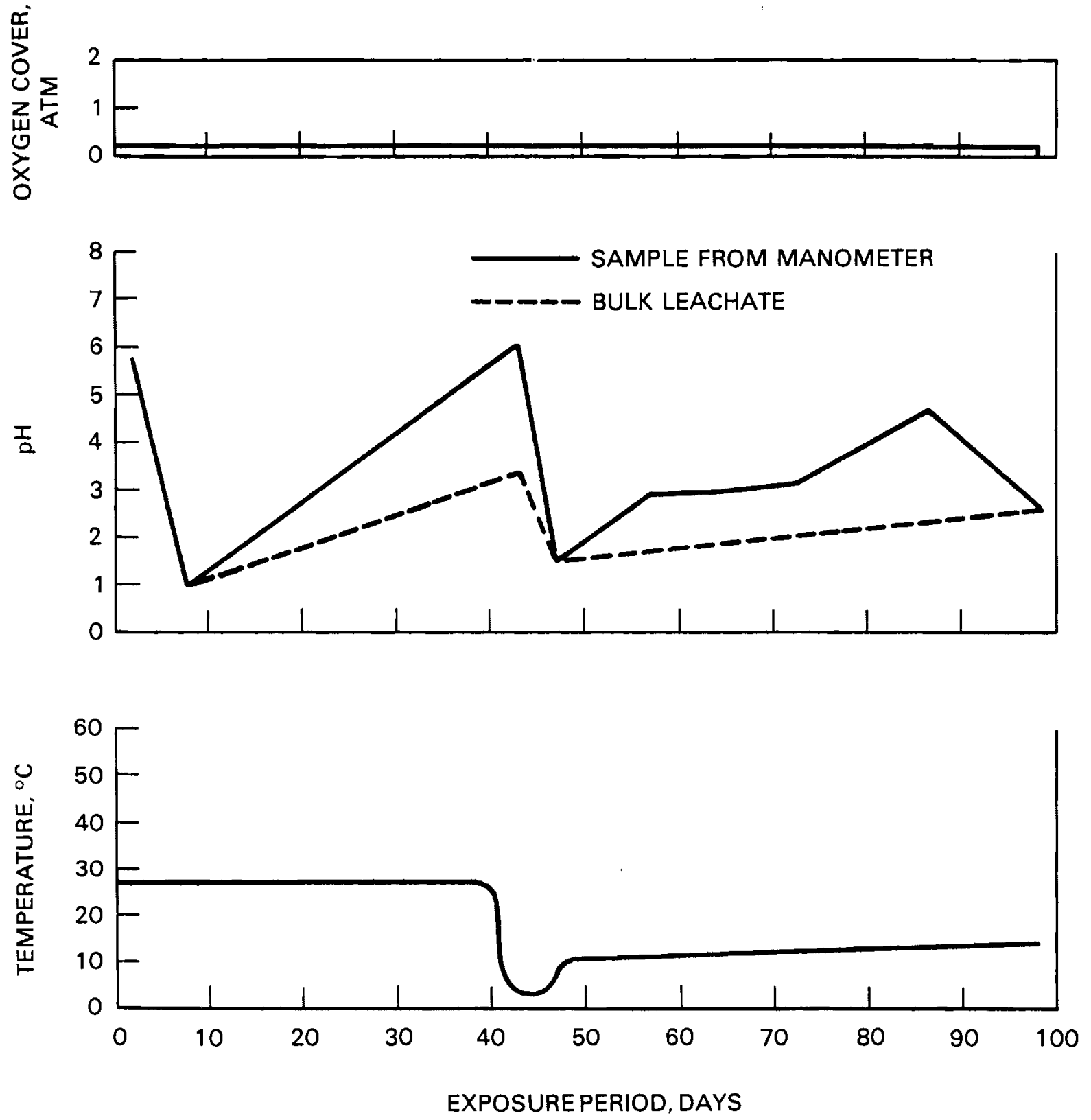

FIGURE A.13. Exposure Conditions for Liner 7 


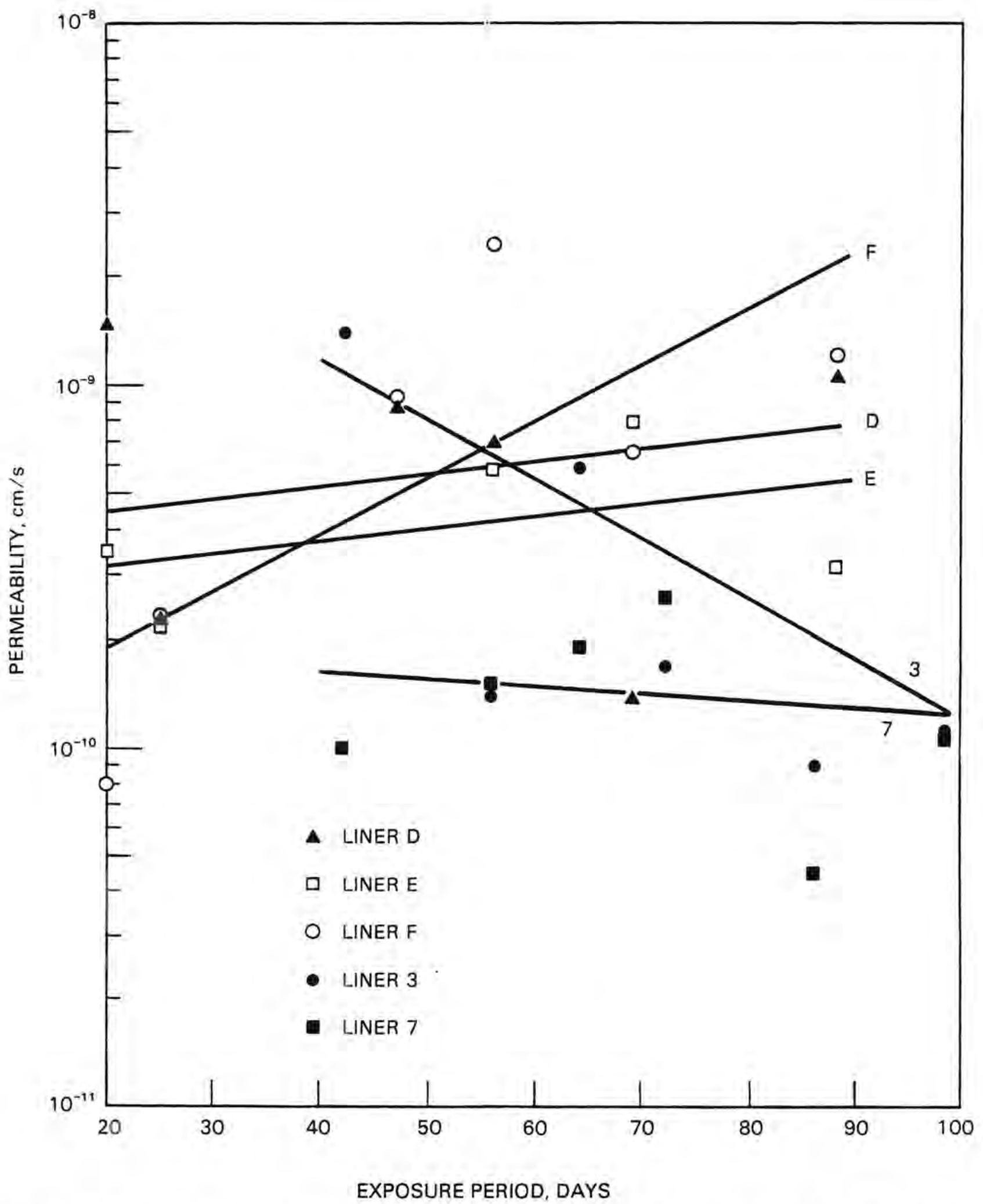

FIGURE A.14. Permeabilities of Liners Exposed to Low Temperature Conditions 


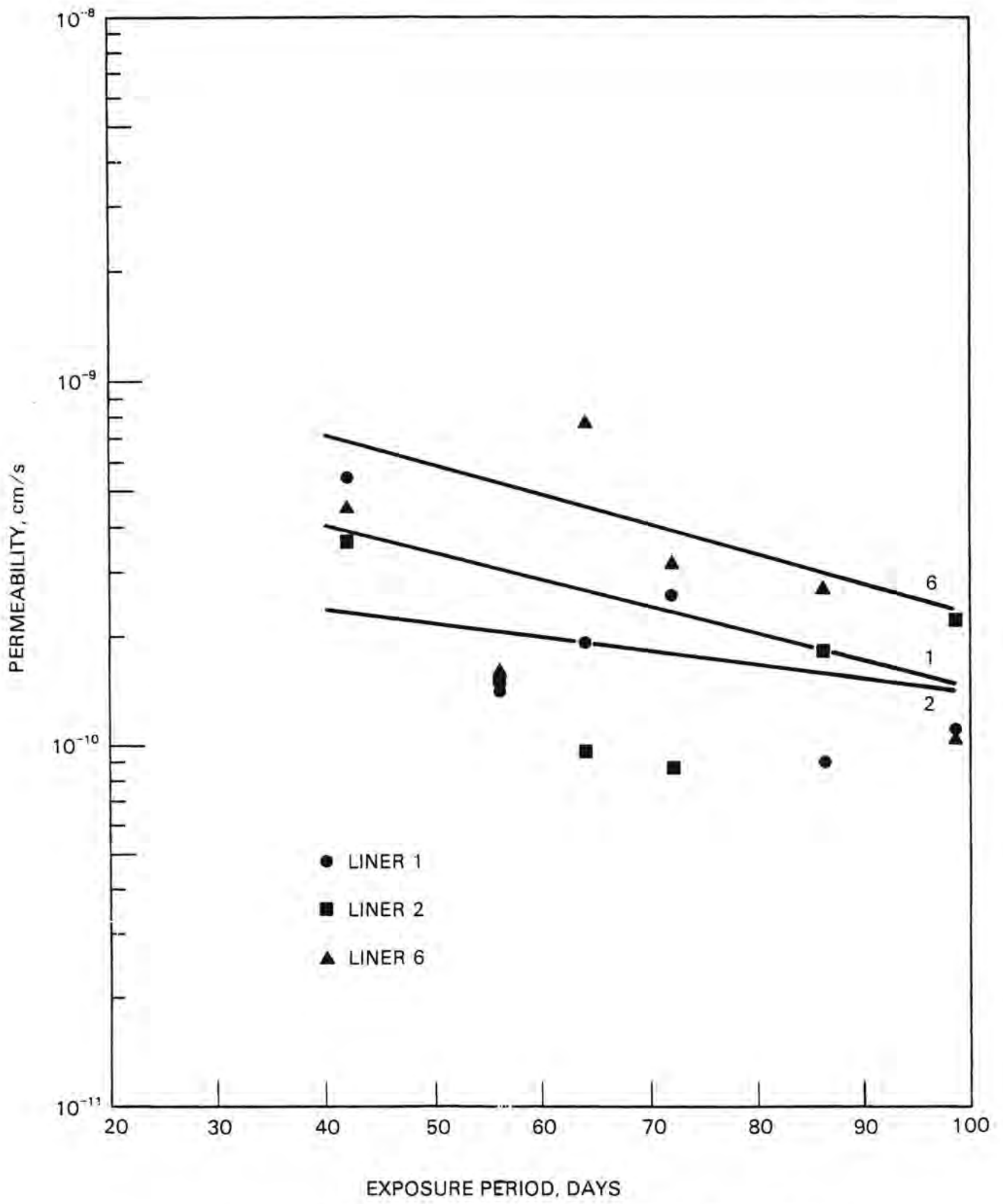

FIGURE A.15. Permeabilities of Liners Exposed to Intermediate Temperature Conditions 


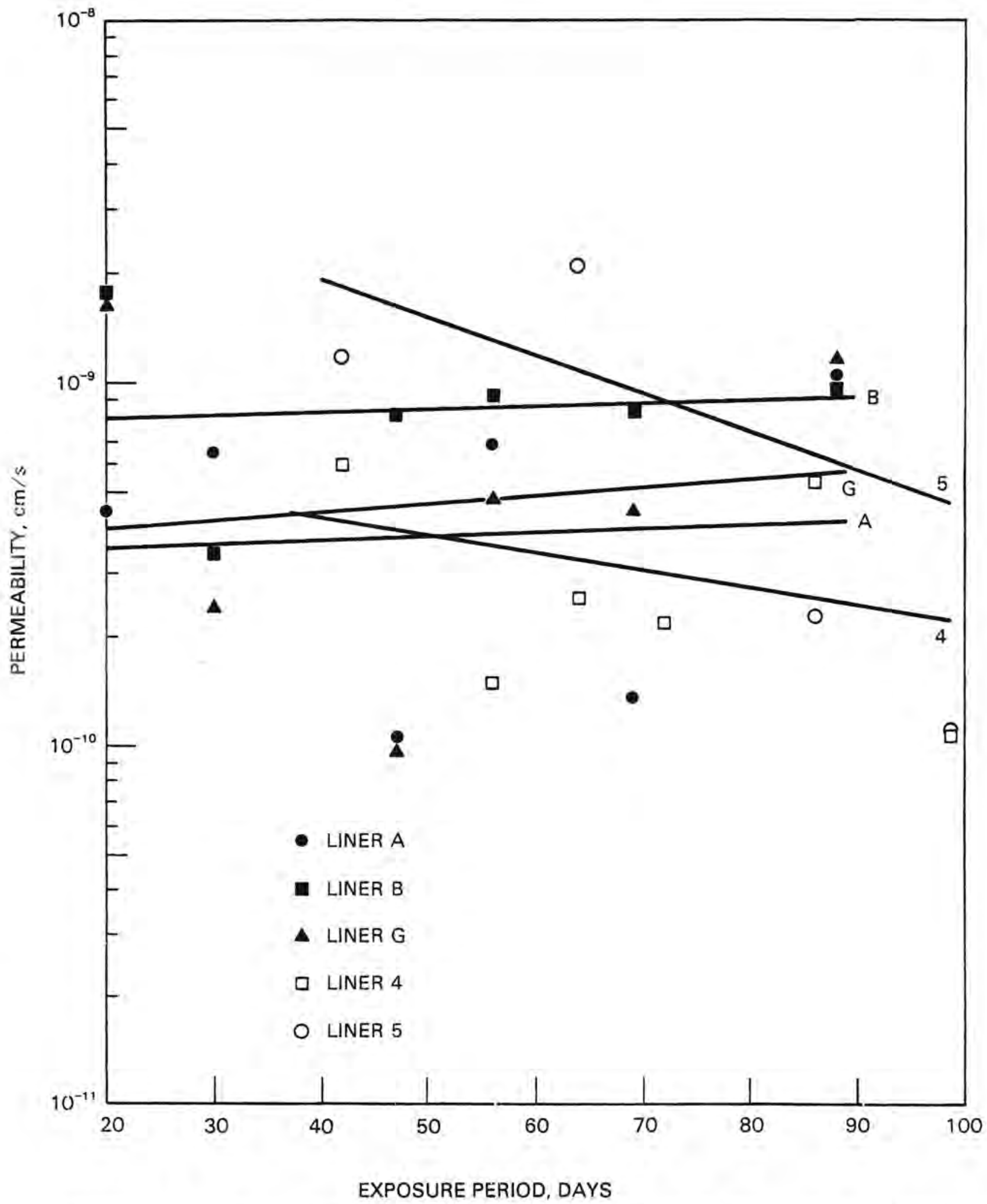

FIGURE A.16. Permeabilities of Liners Exposed to High Temperature Conditions 


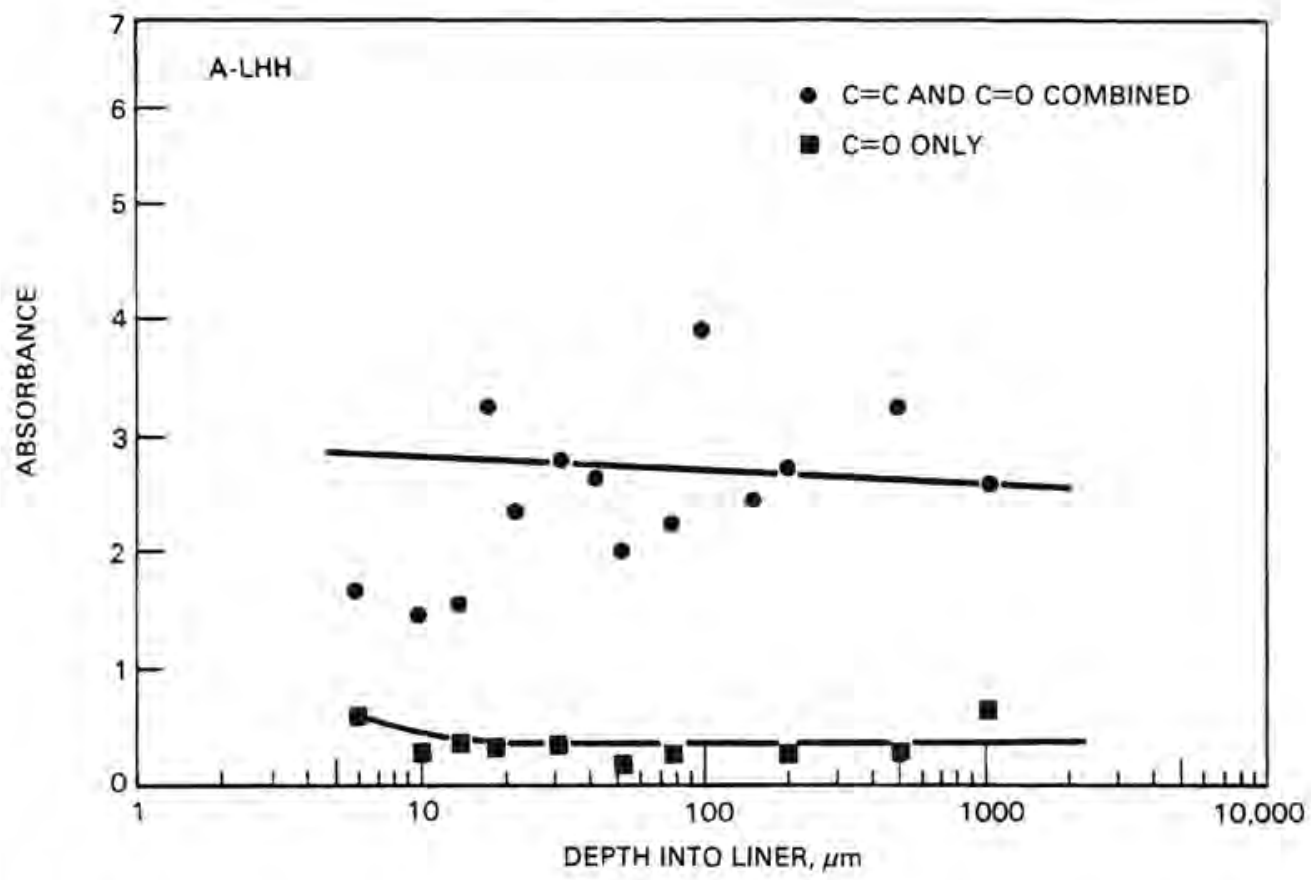

FIGURE A.17. Integrated Absorbance in the Carbonyl and Carbon Double Bond Regions as a Function of Depth into Liner A

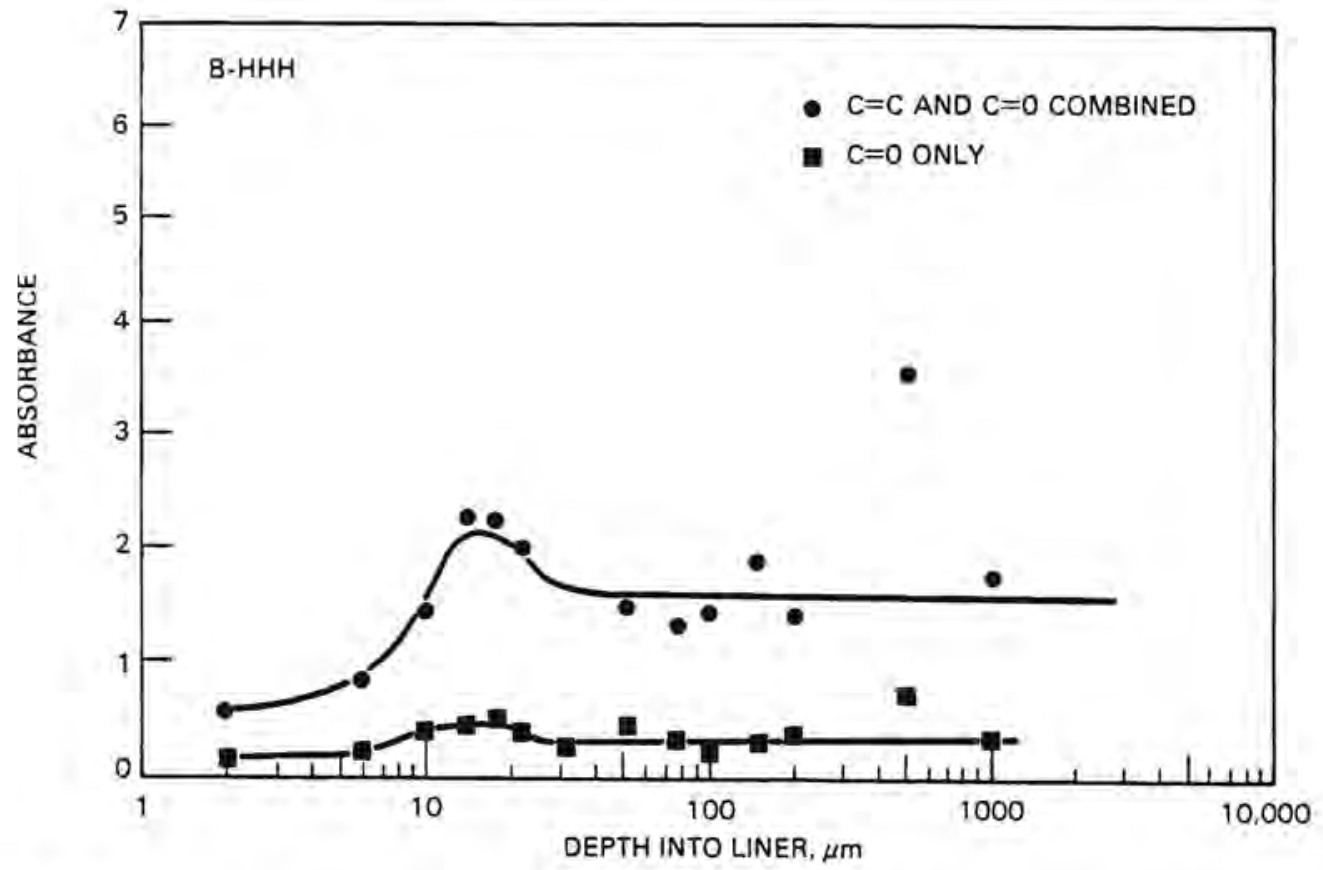

FIGURE A.18. Inteyrated Absorbance in the Carbonyl and Carbon DoubTe Bond Regions as a Function of Depth into Liner B 


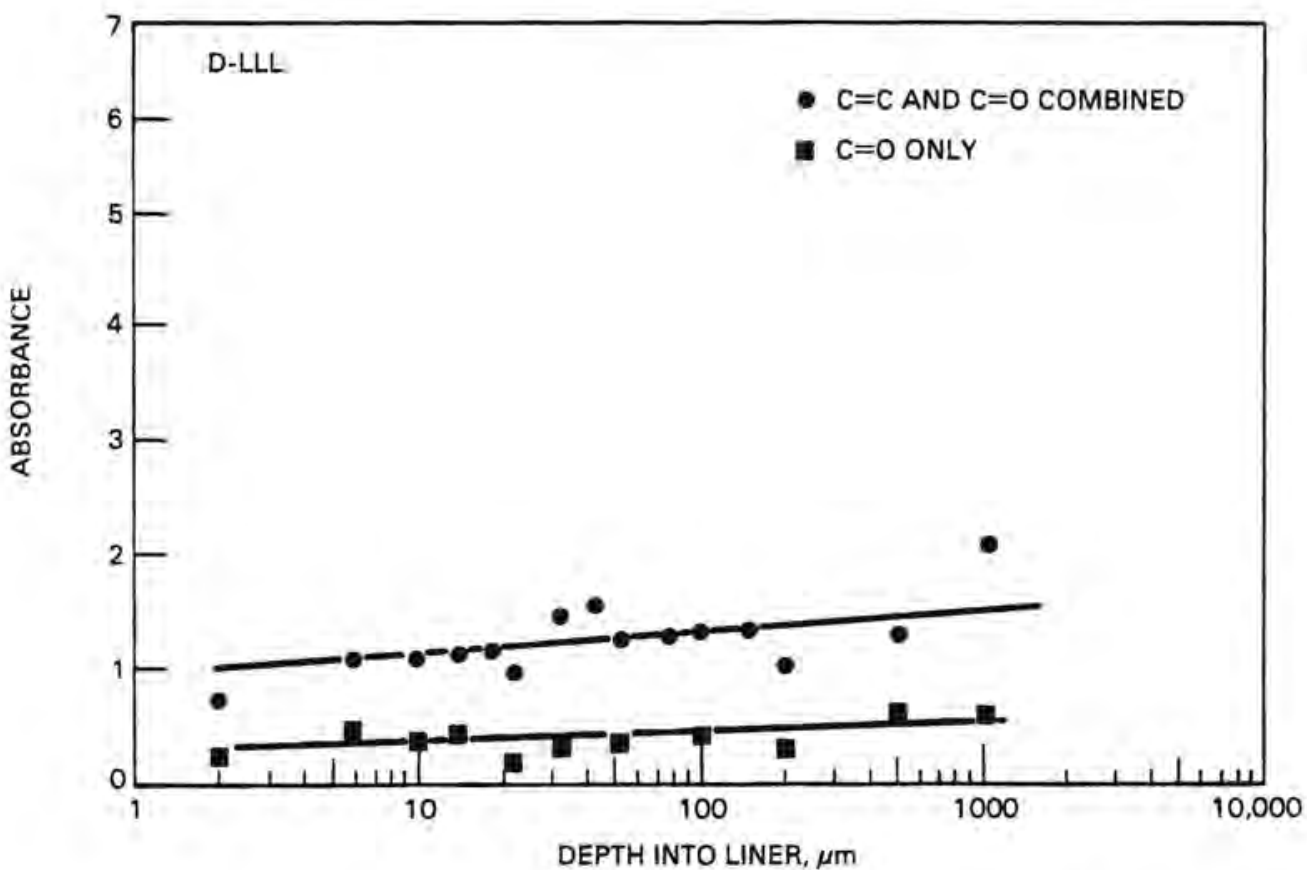

FIGURE A.19. Integrated Absorbance in the Carbonyl and Carbon Double Bond Regions as a Function of Depth into Liner $D$

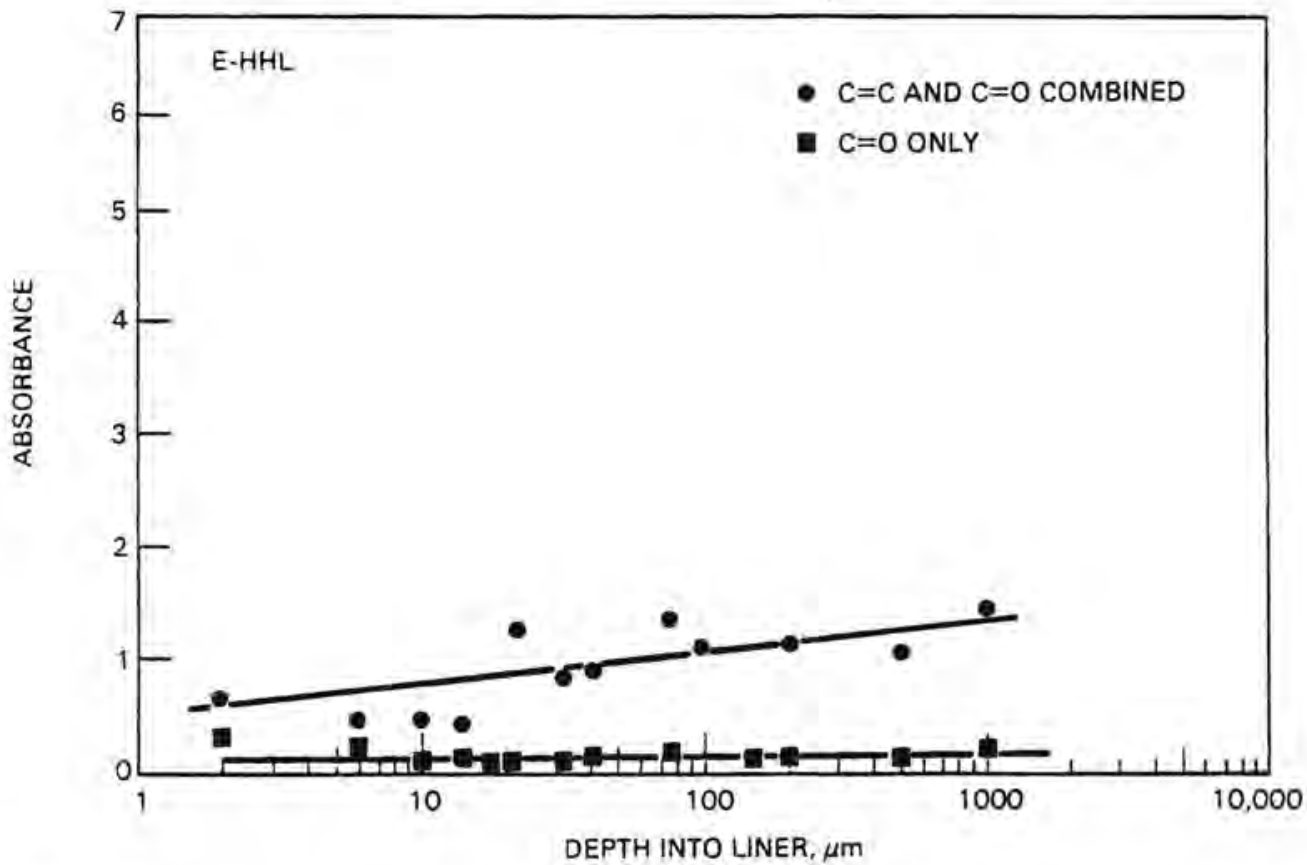

FIGURE A.20. Integrated Absorbance in the Carbonyl and Carbon Double Bond Regions as a Function of Depth into Liner $E$ 


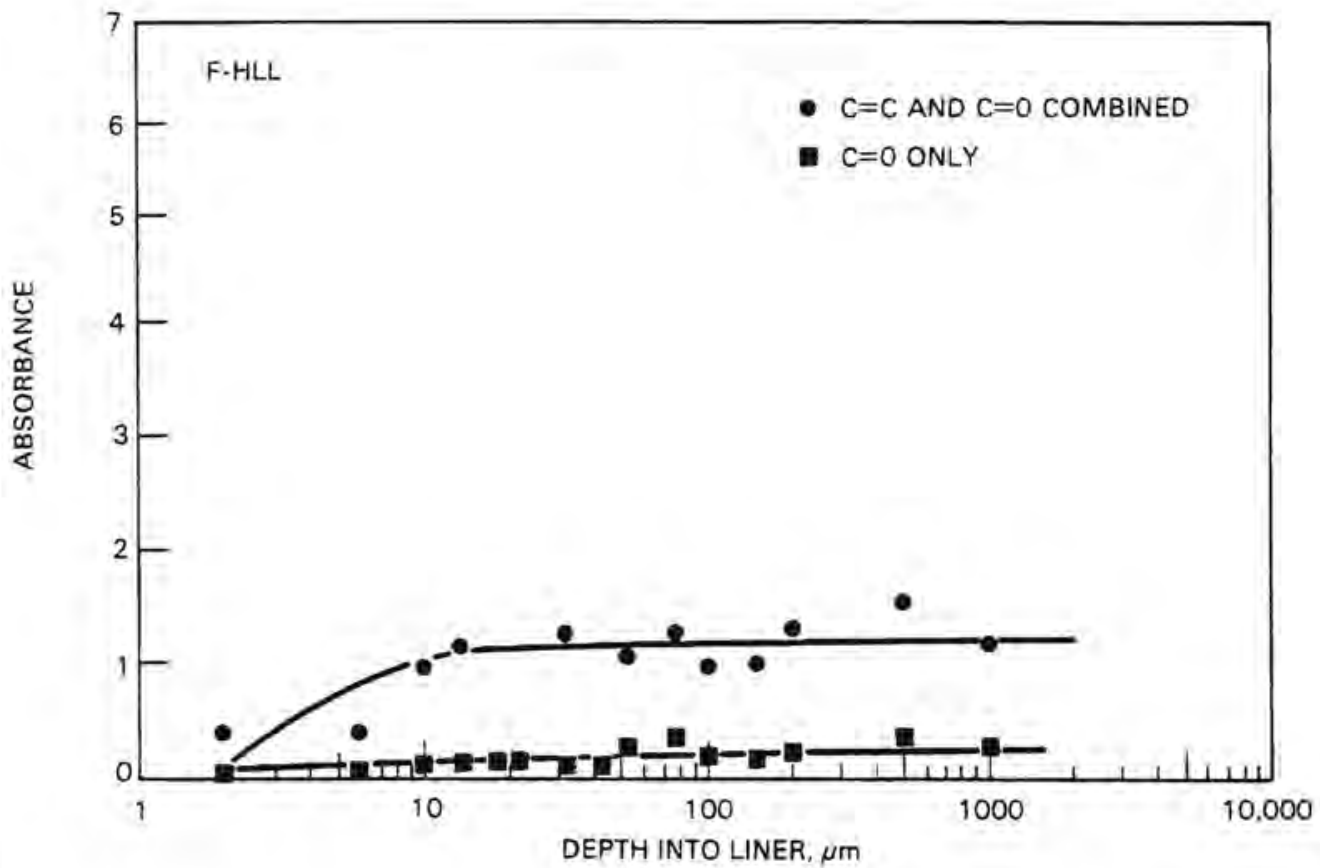

FIGURE A.?.1. Integrated Absorbance in the Carbonyl and Carbon Double Bond Regions as a Function of Depth into Liner $F$

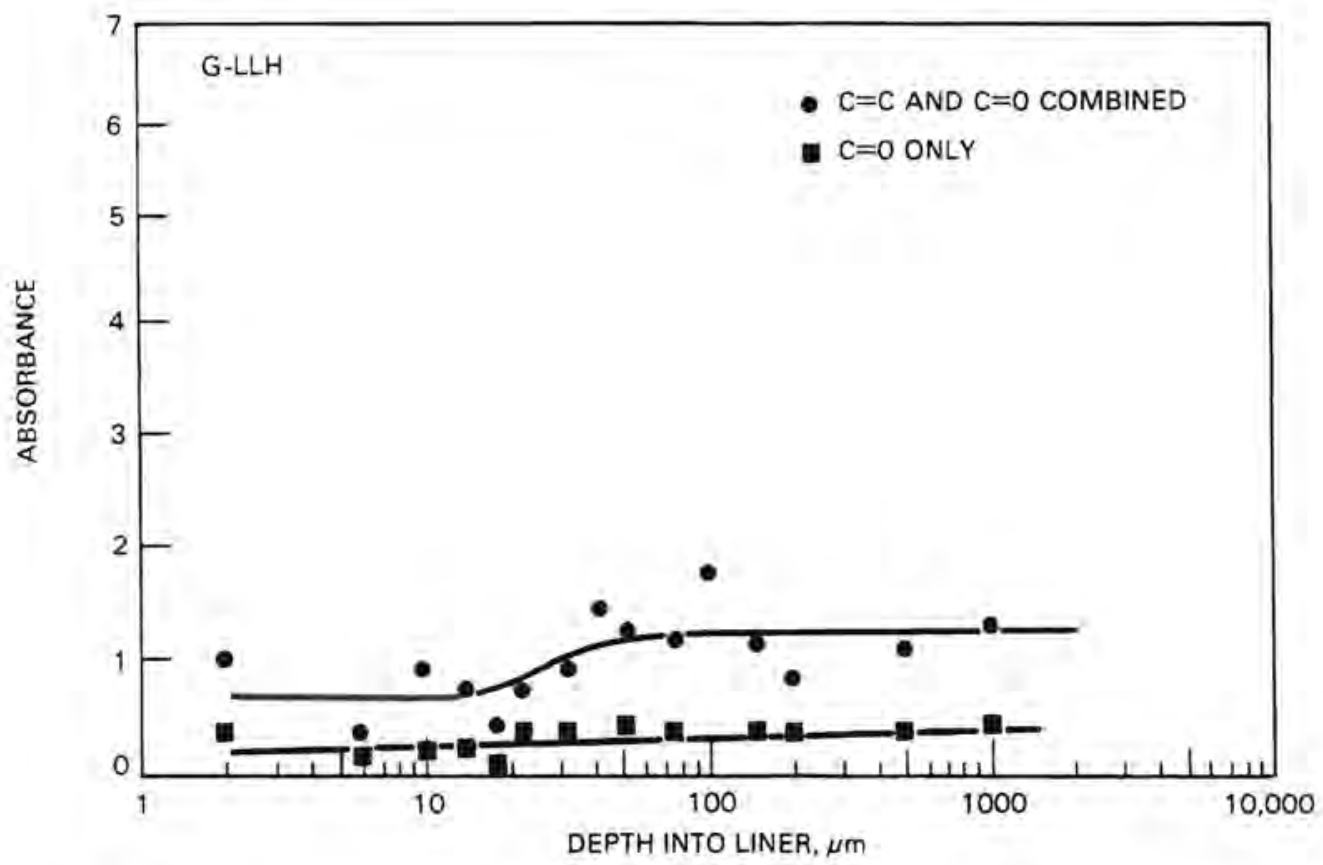

FIGURE A.22. Integrated Absorbance in the Carbonyl and Carbon Double Bond Regions as a Function of Depth into Liner G 


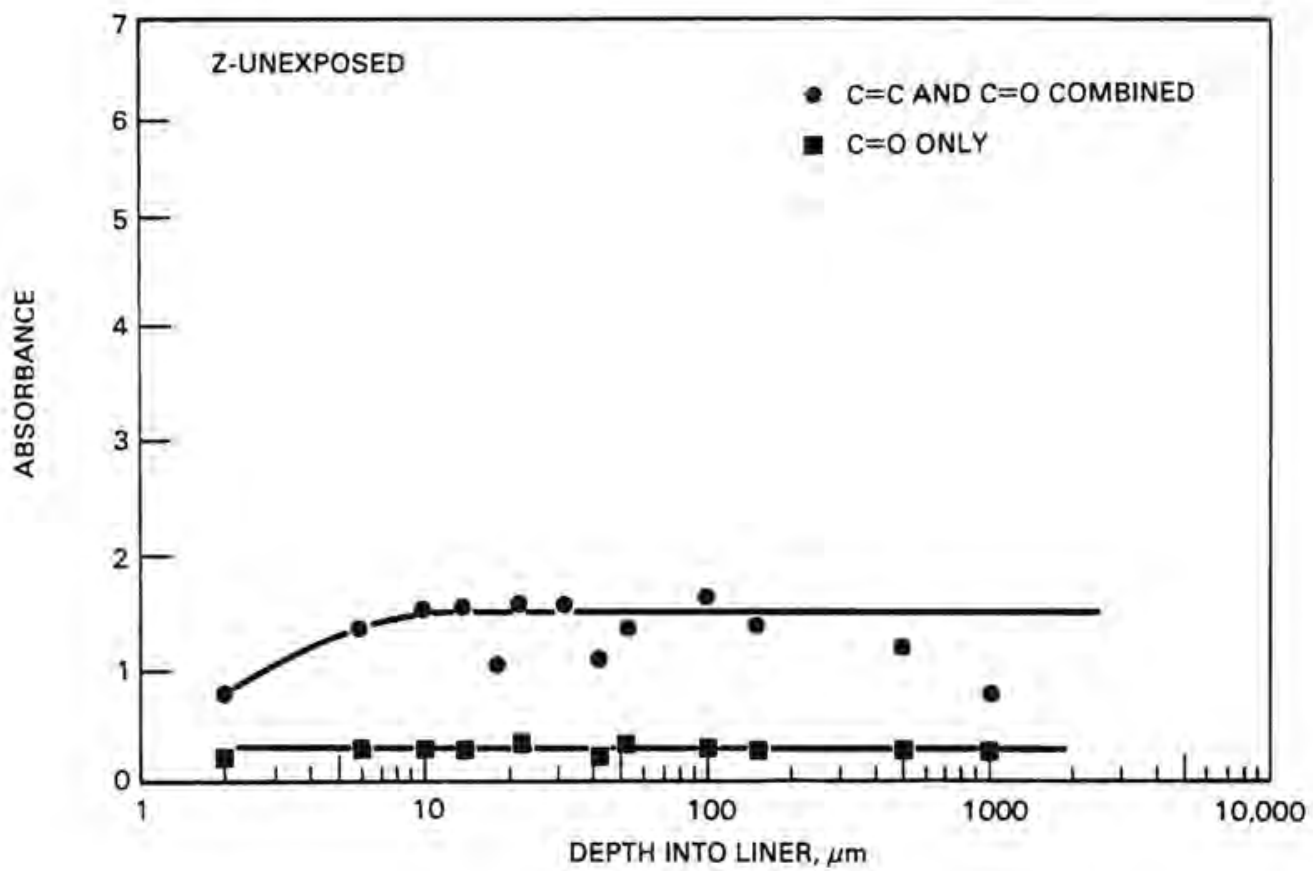

FIGURE A.23. Integrated Absorbance in the Carbonyl and Carbon Double Bond Regions as a Function of Depth into the Control Liner $Z$

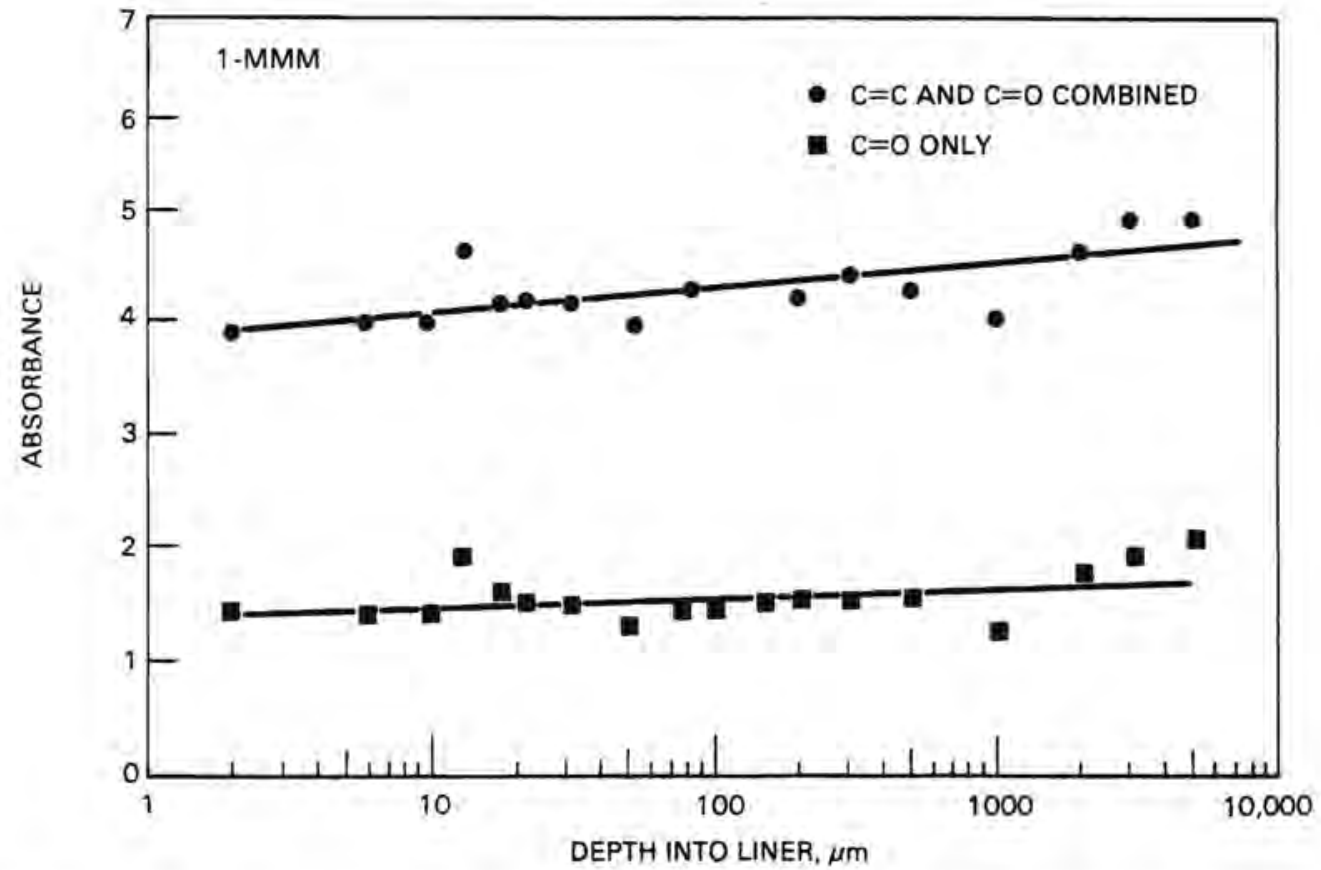

FIGURE A.24. Integrated Absorbance in the Carbonyl and Carbon Double Bond Regions as a Function of Depth into Liner 1 


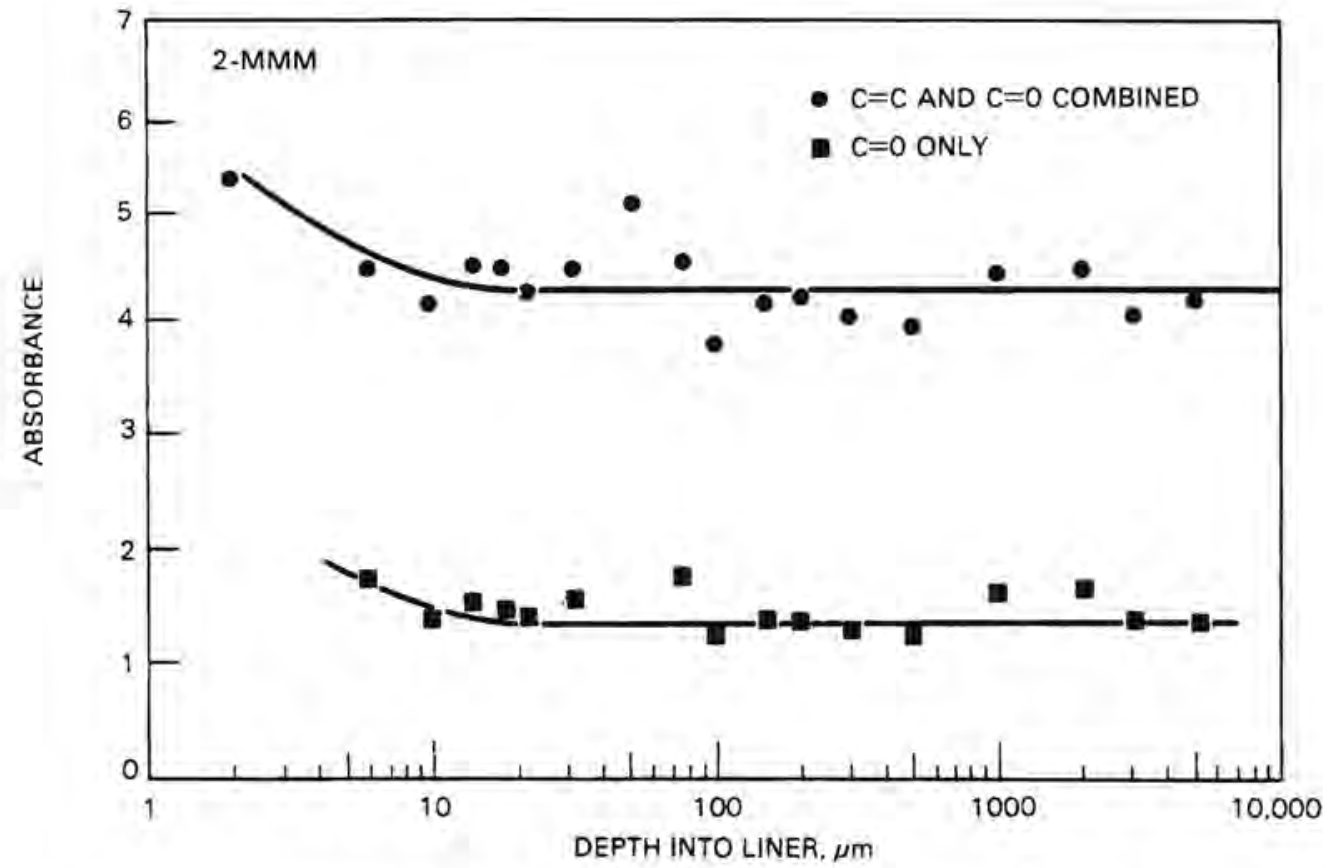

FIGURE A.25. Inteyrated Absorbance in the Carbonyl and Carbon Double Bond Regions as a Function of Depth into Liner 2

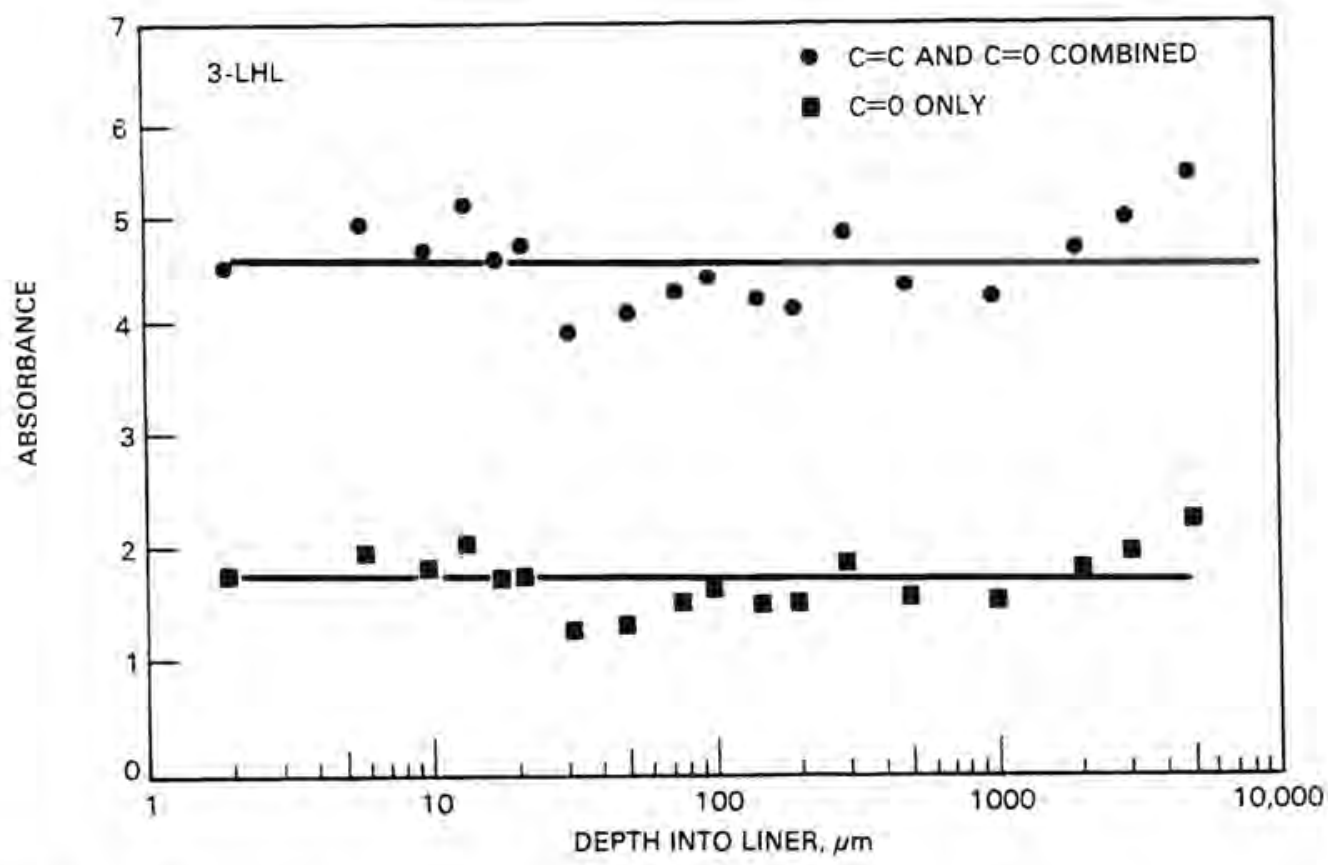

FIGURE A.26. Inteyrated Absorbance in the Carbonyl and Carbon Double Bond Regions as a Function of Depth into Liner 3 


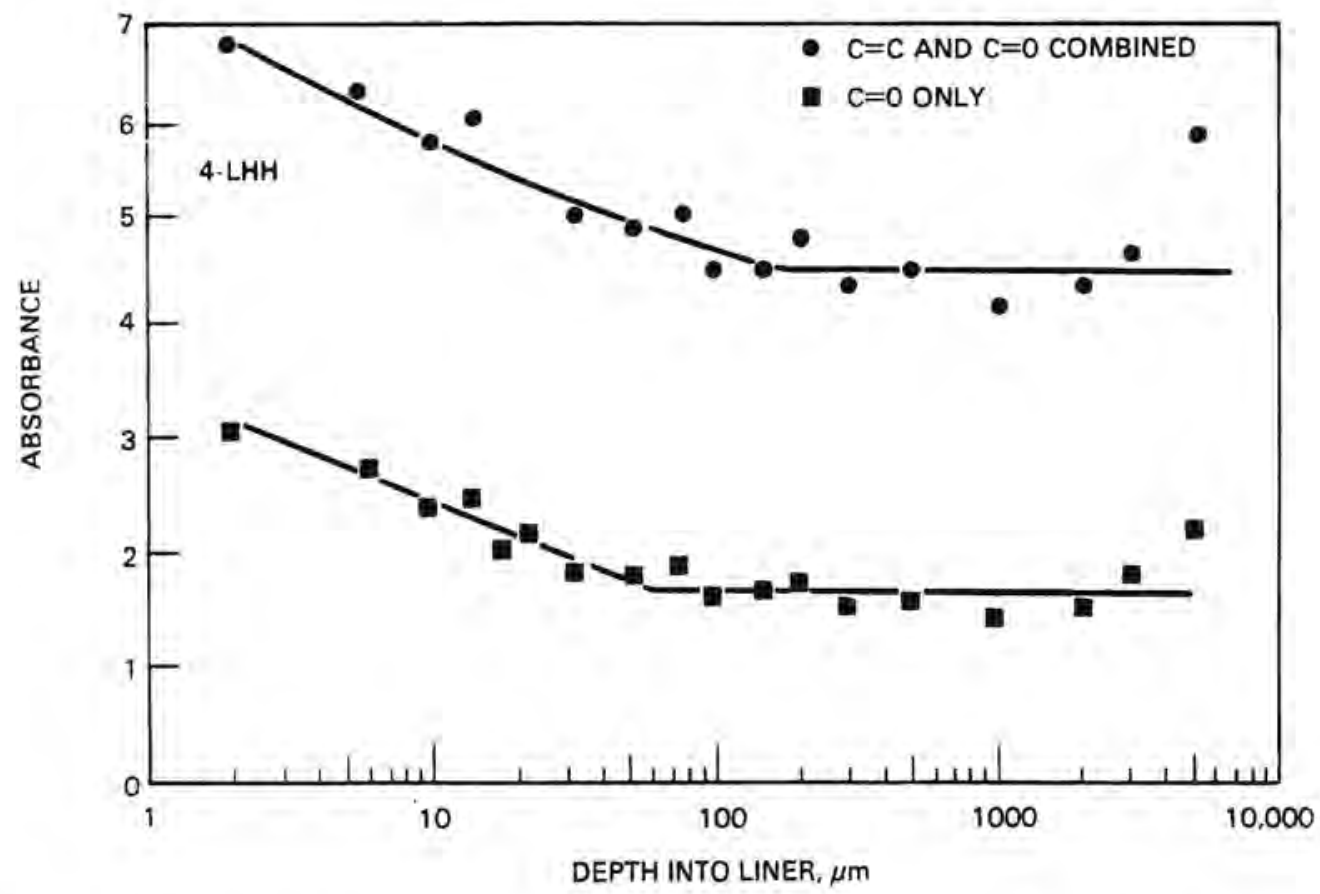

FIGURE A.27. Integrated Absorbance in the Carbonyl and Carbon Double Bond Regions as a Function of Depth into Liner 4

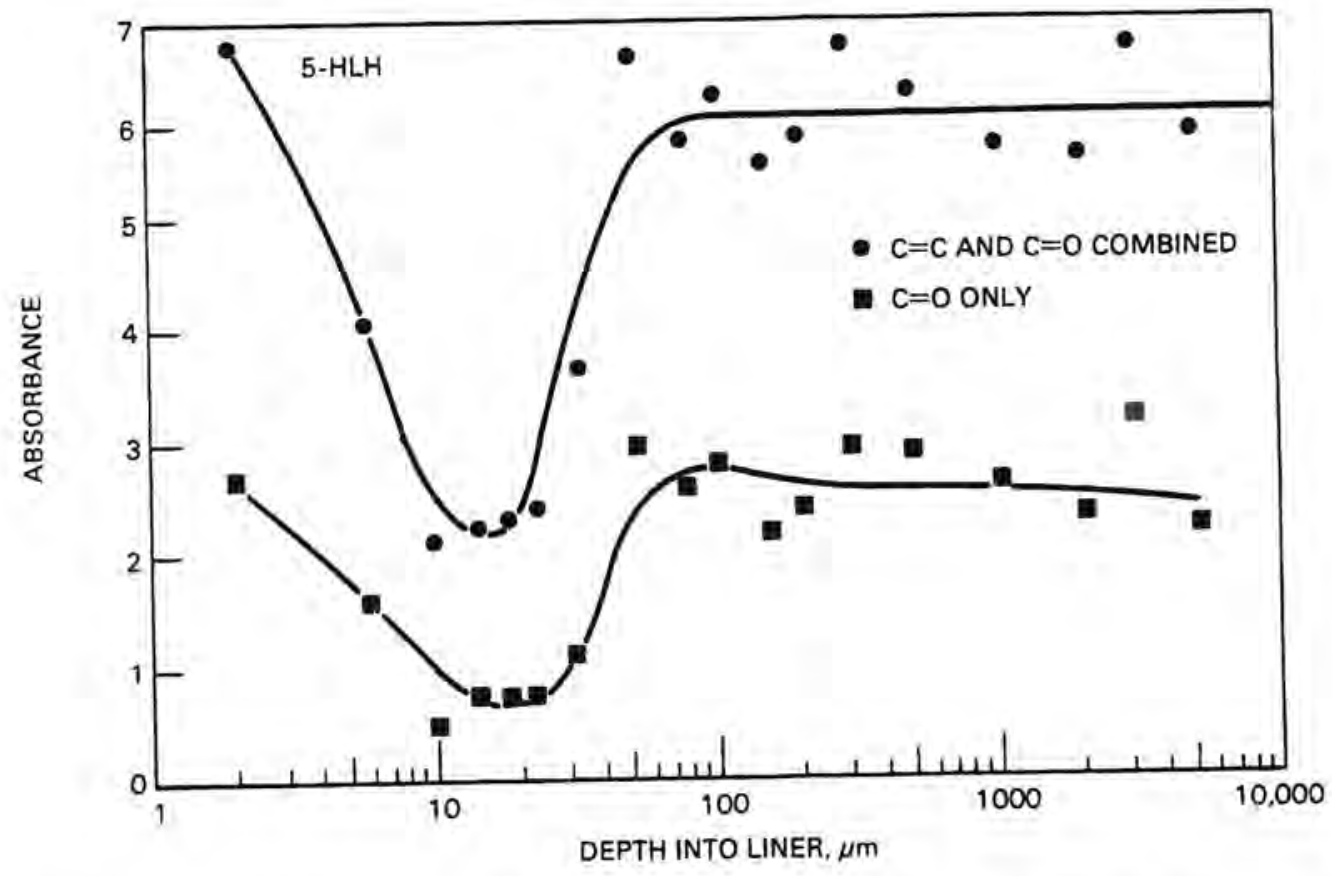

FIGURE A.28. Integrated Absorbance in the Carbonyl and Carbon Double Bond Regions as a Function of Depth into Liner 5 


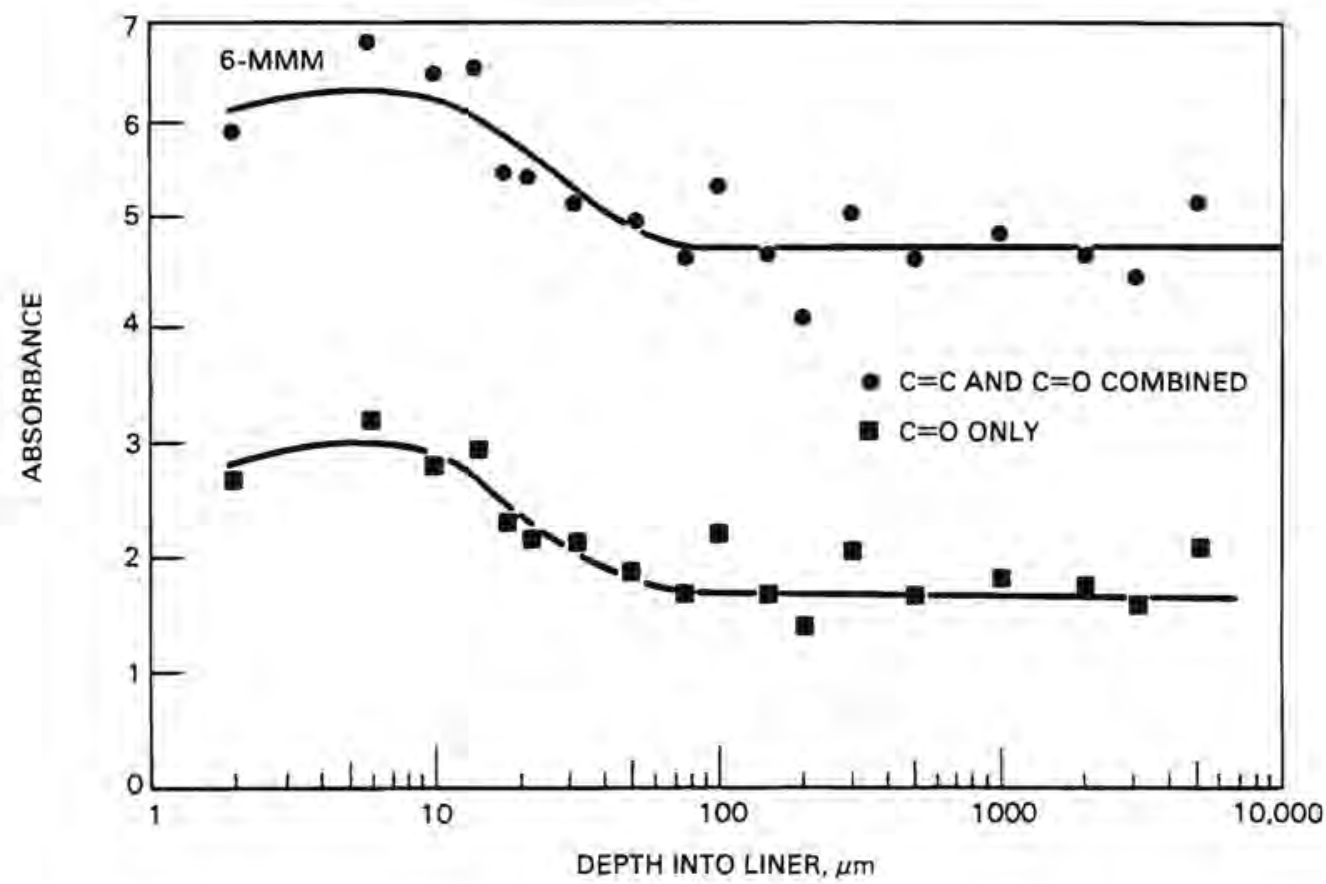

FIGURE A.29. Integrated Absorbance in the Carbonyl and Carbon Double Bond Regions as a Function of Depth into Liner 6

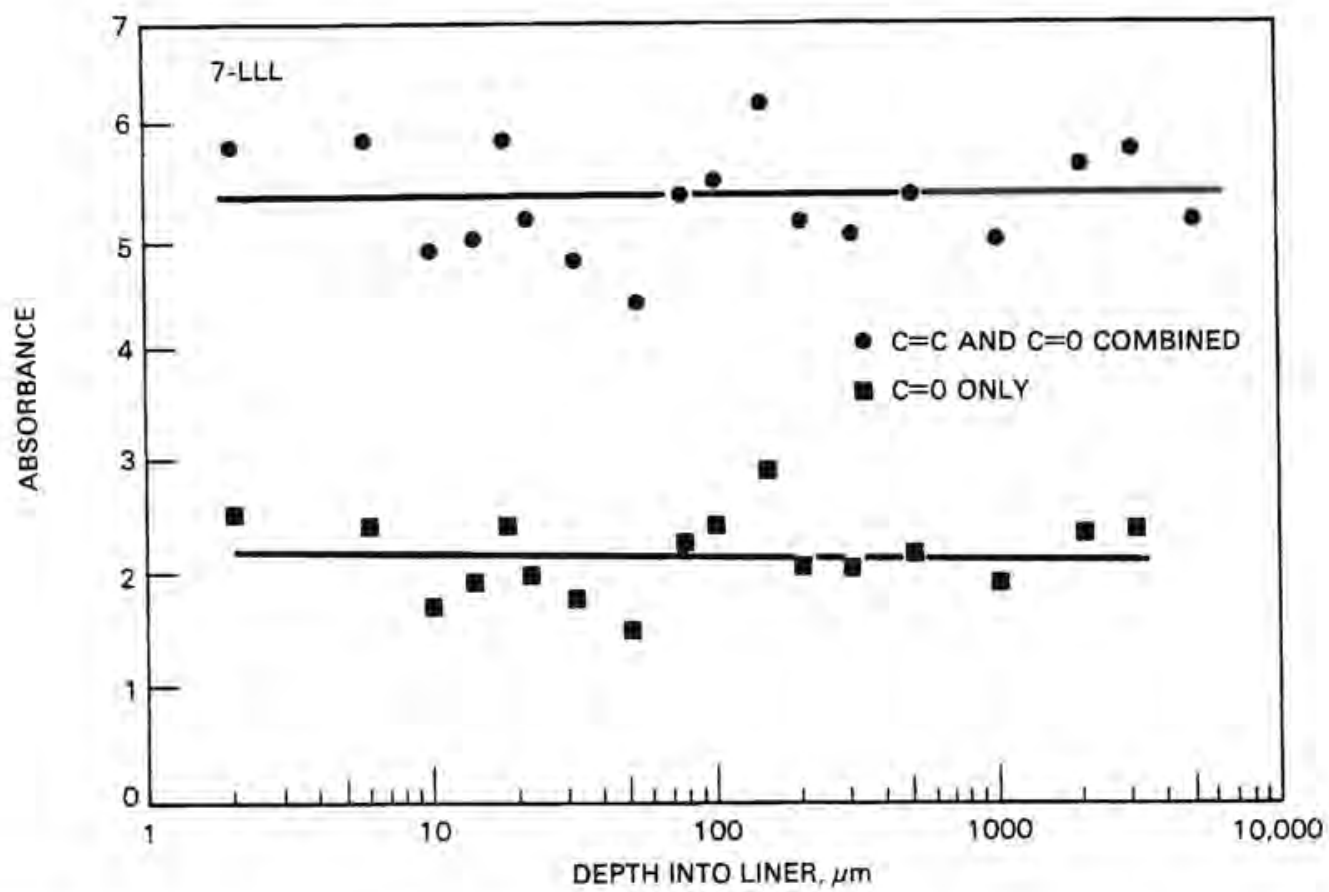

FIGURE A.30. Inteyrated Absorbance in the Carbonyl and Carbon Double Bond Regions as a Function of Depth into Liner 7 


\section{DISTRIBUTION}

No. of Copies

27 DOE Technical Information Center

W. Ackerman

Dept. of Environmental Quality

Land Quality Division

Hathaway Building

Cheyenne, WY 82002

L. Anderson, Director

Bureau of Radiation and

Occupational Health

P.0. Box 2500

Salt Lake City, UT 84110

Alvin Askew

Politech Corporation

2220 Austin National Bank Tower

Austin, TX 78701

E. D. Bailey, Administrator

Texas [lepartment of Health

Radiation Control Branch

1100 West 49 th Street

Austin, TX 78756

R. D. Baird

Ford, Bacon \& Davis Utah

P.0. Box 8009

Salt Lake City, UT 84108

George Birchard

Mail Station 1130-SS

U.S. Nuclear Regulatory

Commission

Washington, DC 20555

Richard Blanton

Acting Director of Radioactive

Materials

Arizona Radiation Regulatory Agency

925 South 52nd Street, Suite 2

Tempe, AZ 85281
No. of

Copies

K. J. Bush

Geochemistry and Environmental

Chem. Res. Inst.

2693 Commerce Road

Rapid City, SD 57701

R. H. Campbe11, Project

Manager

Uranium Mill Tailings Project Office

U.S. Department of Energy

P.0. Box 5400

Albuquerque, NM 87115

Bill Chappell

University of Colorado

1100 14th Street

Denver, C0 80202

E. Delaney, Remedial Actions

Program Office of Nuclear Waste Management

U.S. Department of Energy, NE-301

Washington, DC 20545

David Dreesen

Group LS-6, MS-495

Los Alamos National Laboratory

P.0. Box 1663

Los Alamos, NM 87545

L. Fitzrandolph

Arizona Atomic Energy Commission 2929 West Indian School Road

Phoenix, AZ 85017

L. Frank

Oregon Dept. of Energy

111 Labor and Industries

Building

Salem, OR 97310 
No. of

Copies

R. Funderberg

Dept. of Health and Welfare

State House

Boise, ID 83707

T. M. Gerusky, Director

Bureau of Radiation Protection

P.0. Box 2063

Harrisburg, PA 17120

Donald H. Groelsema, Remedial

Actions Program

Office of Nuclear Waste Management

U.S. Department of Energy, NE-301

Washington, DC 20545

A. J. Hazle, Director

Colorado Department of Health

Radiation and Hazardous Waste Division

4210 East 11 th Avenue

Denver, CO 80220

S. A. Higdon

U.S. Department of Energy

Region VIII Office

1075 South Yuk on Street

L.akewood, C0 80226

Cecil Hoffman

U.S. Department of Interior

AS/PBA, Room 5119

19 th and C Streets, NW

Washington, DC 20240

E. L. Keller, Director

Technical Services Division

DOE Oak Ridge Operations Office

P.0. Box E

Oak Ridge, TN 37830
No. of

Copies

W. Kisieleski

Argonne National Laboratory

9700 South Cass Avenue

Argonne, IL 60439

A. Kluk, Remedial Actions

Program

Office of Nuclear Waste

Management

U.S. Department of Energy, NE-301

Washington, DC 20545

N. D. Kretz

Argonne National Laboratory

9700 South Cass Avenue,

Bldg. 202

Argonne, IL 60439

D. E. Large, Program Manager

Radioactive Waste Management

Program

Oak Ridge Operations Office

P.0. Box E

Oak Ridge, TN 37830

S. Lichtman

U.S. Environmental Protection Agency

Criteria and Standards Division

Office of Radiation Programs

Washington, DC 20460

Dr. Gergely Markos

Research Institute for

Geochemistry and Environmental

Chemistry

2693 Commerce Road

Rapid City, SD 57701 
No. of

Copies

M. L. Matthews, Project Engineer Uranium Mill Tailings Project Office

U.S. Department of Energy

P.0. Box 5400

Albuquerque, NM 87115

J. W. Mckiernan, Organization 4542

Sandia National LaboratoryAlbuquerque

P.0. Box 5800

Albuquerque, NM 87185

A. A. Metry

Weston

Weston Way

West Chester, PA 19380

D. K. Mount, Director

North Dakota State Dept. of Health

Div. of Environmental

Engineeriny

1200 Missouri Avenue, Room 304

Bismarck, Ni4 58505

William E. Mott, Director

Environmental and Safety

Engineering Division

U.S. Department of Energy, EP-14

Washington, DC 20545

Nari Narasimhan

Earth Sciences Division

Lawrence Berkeley Laboratory

University of California

Berkeley, CA 94720

R. Neff

Mound Facility

c/o Dayton Area Office

P.0. Box 66

Miamibury, $\mathrm{OH} 45342$
No. of

Copies

John D. Nelson

Geotechnical Engineering

Department

Colorado State University

Ft. Collins, CO 80523

William Nixon

Office of Nuclear Materials, Safety and Safeguards

U.S. Nuclear Regulatory Commission

Mail Station 396-SS

Washington, DC 20555

Robert Overmyer

Ford, Bacon \& Davis Utah

P.0. Box 8009

Salt Lake City, UT 84108

K. R. Porter

Dames and Moore

1626 Cole Boulevard

Golden, C0 80401

Robert W. Ramsey, Jr., Program Manager

Remedial Actions Program, NE-301

U.S. Department of Energy

Washington, DC 20545

Vern C. Rogers, President

Rogers and Associates

Engineering

445 East 200 South, Suite 303

Salt Lake City, UT 84111

A. Ryon

Oak Ridge National Laboratory

P.0. Box $X$

Oak Ridge, TN 37830

Ross A. Scarano, Chief

Uranium Recovery License Branch

U.S. Nuclear Regulatory Commission

Mail Station 483-SS

Washington, DC 20555 
No. of

Copies

W. M. Shaffer

Uranium Recovery Licensing Branch

U.S. Regulatory Commission

Mail Station 461-SS

Washington, DC 20555

George Stukenbroker

NLO, Inc.

P.0. Box 39158

Cincinnati, $\mathrm{OH} \quad 45239$

T. Tamura

Head, Earth Sciences Section

Environmental Sciences Division

P.0. Box $X$, Building 1505

Oak Ridge National Laboratory

Oak Ridge, TN 37830

J. G. Themelis, Director

Engineering and Safety Division

DOE Grand Junction Office

2597 B-3/4 Road (South Redlands)

P.0. Box 2567

Grand Junction, CO 81501

Martin Tierney

Division 9733

Sandia Laboratories

P.0. Box 5800

Albuquerque, NM 87185

A. Topp, Chief

Radiation Protection Bureau

P.0. Box 968

Santa Fe, NM 87503

H. Tso, Executive Director

Environmental Protection Commission

The Navajo Nation

Window Rock, $A Z$
No. of

Copies

A. S. White, Earth Sciences Division

Lawrence Berkely Laboratory

Berkeley, CA 94720

5 Battelle Memorial Institute

Beverly Rawles

Office of Nuclear Waste

Isolation

$505 \mathrm{King}$ Avenue

Columbus, $\mathrm{OH} 43201$

ONSITE

4 DOE Richland Operations Office

0. J. Elgert

H. E. Ransom

J. J. Schreiber

J. D. White

2 Rockwell Hanford Operations

D. L. Lane

S. J. Phillips

39 Pacific Northwest Laboratory

S. M. Barnes

P. A. Beed low

W. F. Bonner

J. L. Buelt (20)

T. D. Chikalla

J. F. Cline

G. W. Gee

M. S. Hanson

S. D. Harris

J. N. Hartley

J. M. Latkovich

D. H. Mitchell

J. R. Morrey

R. E. Nightingale

J. V. Robinson

Technical Information (5)

Publishing Coordination (VG) (2) 